\title{
Optimal Groundwater Management under Climate Change and Technical Progress.
}

\author{
Nicolas E. Quintana Ashwell ${ }^{\dagger}$ \\ 332-B Waters Hall \\ Kansas State University \\ Manhattan, KS 66506 \\ Jeffrey M. Peterson \\ Water Resources Center \\ 173 McNeal Hall \\ 1985 Buford Avenue \\ St. Paul, MN 55108 \\ Nathan P. Hendricks \\ 326 Waters Hall \\ Kansas State University \\ Manhattan, KS 66506
}

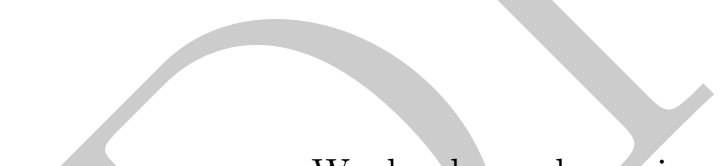

We develop a dynamic model of groundwater extraction for irrigation where climate change and technical change are included as exogenous state variables in addition to the usual state variable of the stock of groundwater. Our key contributions are (i) an intuitive description of the conditions under which groundwater extraction can be non-monotonic, (ii) a numerical demonstration that extraction is non-monotonic in an important region overlying the Ogallala Aquifer, and (iii) the predicted gains from management are substantially larger after accounting for climate and technical change. Intuitively, optimal extraction is increasing in early periods when the marginal benefits of extraction are increasing sufficiently fast due to climate and technical change compared to the increase in the marginal cost of extraction. In contrast, most previous studies include the stock of groundwater as the only state variable and recommend a monotonically decreasing

*This material is based upon work that is supported by the National Institute of Food and Agriculture, U.S. Department of Agriculture, under award number 2015-67023-22934.

${ }^{\dagger}$ Nicolas E. Quintana AShwell is a Ph.D. candidate at Kansas State University, Department of Agricultural Economics. Jeffrey M. Peterson is a Professor in the Department of Applied Economics and Director of the Water Resources Center at the University of Minnesota, Twin Cities. Nathan P. Hendricks is an Associate Professor in the Department of Agricultural Economics at Kansas State University 
(C) 2018. This manuscript version is made available under the CC-BY-NC-ND 4.0 license http://creativecommons.org/licenses/by-nc-nd/4.0/

extraction path. We conduct numerical simulations for a region in Kansas overlying the Ogallala Aquifer and find that optimal groundwater extraction peaks 23 years in the future and the gains from management are large $(29.5 \%)$. Consistent with previous literature, the predicted gains from management are relatively small $(6.1 \%)$ when ignoring climate and technical change. The realized gains from management are not substantially impacted by incorrect assumptions of climate and technical change when formulating the optimal plan.

\section{Introduction}

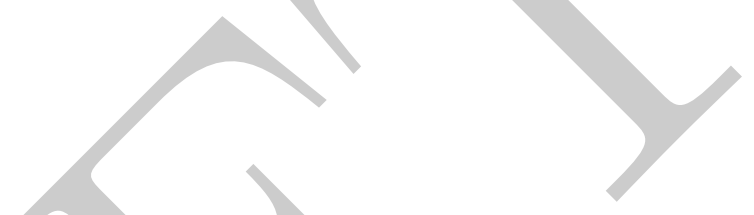

The economic dependency on irrigation of large agricultural regions such as the Great Plains in the United States makes aquifer depletion a much-discussed policy and research issue. Premature aquifer depletion can be costly. Temporally misallocating the resource causes suboptimal levels of social welfare derived from mining the resource over time. Furthermore, premature depletion results in a diminished ability to cope with the added stress of higher evapotransporative needs associated with climate change.

Despite the likely shift in groundwater demand over time, it is seldom accounted for in the groundwater management literature. The shifts in temperature levels and seasonal distribution of precipitation associated with climate change are expected to increase the demand for irrigation groundwater over time. Technical progress in the form of improvements in crop varieties that result in increased evapotranspiration productivity are similarly associated with shifts in the demand for irrigation groundwater. In this paper, climate change and technical progress are exogenous state variables that modify the periodical value marginal product of groundwater (VMP) in an optimal control problem.

We find that the gains from management are orders of magnitude larger than the case with static groundwater demand. We also find that optimal extraction reaches a peak in the future whereas extraction is monotonically decreasing with static groundwater demand.

There is a long history of literature studying groundwater as a common pool resource, in which a socially optimal extraction path is compared to the competitive, or rather non-intervention, extraction path. The implicit argument is that policy intervention is 
worthwhile if there is a significant difference between optimal and competitive paths in terms of social welfare. In a seminal work, Gisser and Sanchez (1980) found that the quantitative difference between competitive extraction and a socially optimal groundwater extraction rule was negligible. These results, referred to as the "Gisser Sanchez Effect" (GSE), have provided an economic rationale for opposing interventions that conserve groundwater for future use and focus on allocation of groundwater among different uses rather than over time (Gisser, 1983). The policy implications are important. For instance, the High Plains Ogallala Regional Aquifer Study commissioned by the Department of Commerce and the US Congress in 1982 predicted little to no difference in outcomes between a non-intervention projection and a management scenario; no significant management initiatives were implemented but the predictions in the study failed because the assumed dynamics of some factors were incorrect (Peterson and Bernardo, 2003).

Although the GSE persisted in the dynamic solutions in numerous studies since the 1980s, it has been increasingly clear that the GSE resulted from rather stringent and unrealistic assumptions (see Koundouri, 2004, for a critical survey). One of the key assumptions in Gisser and Sanchez (1980), and most of the models that followed, was that of a static demand for extracted groundwater. Brill and Burness (1994) found that the GSE is not robust to the assumption of static demand and that growing demand will lead to an optimal extraction path with periods of both increasing and decreasing rates of pumping. Models with static demand involve only one dynamic state variable - namely the water table height - and impose a monotonic extraction path that asymptotically reaches a steady state. However, historic data are generally consistent with non-monotonic extraction paths. Steward and Allen (2016) show that groundwater extraction paths follow curves similar to the Hubert curve in oil use studies. They estimate that peak "groundwater depletion caused by overtapping", i.e. extraction rates beyond the rate of available recharge, has already occurred in many areas of the high Plains Aquifer while other areas are predicted to face peak extraction levels in the future. 
Most groundwater economics studies assume static demand for groundwater (an incomplete list includes Gisser and Sanchez, 1980; Feinerman and Knapp, 1983; Nieswiadomy, 1985; Negri, 1989; Pulido-Velazquez et al., 2008; Esteban and Albiac, 2011; de Frutos Cachorro et al., 2014; and Esteban and Dinar, 2016). Few exceptions have incorporated non-static demand induced by additional control variables. Kim et al. (1989) presented an $n$-stage optimal control problem that incorporates separate groundwater demand curves for a set of crops over which the planner optimized intraseasonally resulting in a possibly shifting aggregate groundwater demand curve. Another exception is the approach by Burness and Brill (2001) and Quintana-Ashwell and Peterson (2015) which employs a model of substitutable irrigation capital in which investments in irrigation capital resulted in changing value marginal product of pumped groundwater over time.

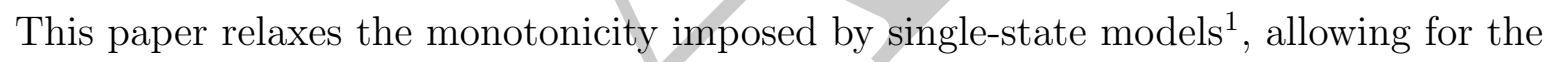
possibility of non-monotonic paths. The formulation incorporates time-varying groundwater demand, explicitly linking the demand shifts to climate change and technical progress. Increases in precipitation result in inward shifts of the demand curve while increasing potential evapotranspiration result in outward shifts of demand. Technical progress causes the marginal yalue product of groundwater to increase over time in a manner consistent with increasing water productivity of irrigated crops. Optimal extraction is increasing when marginal benefits are increasing faster than marginal costs, as in early periods, then decreasing once marginal costs increase faster than marginal benefits. It is shown that it may be optimal for a manager to allow higher rates of extraction in the near future; for instance, results from Sheridan County, KS, indicate that peak groundwater demand occurs 23 years into the future.

While climate change and technical progress make groundwater for irrigation more valuable and productive, the decline in the stocks of groundwater results in increasing marginal pumping costs due to increasing pumping lifts and decreasing groundwater well

\footnotetext{
${ }^{1}$ See theorem 9.5.1 in Leonard and Van Long, 1992, for an intuitive proof of this result.
} 
yields. The net effect of these counteracting forces on the optimal extraction path is ambiguous. Furthermore, when climate, technology, or both are assumed static, the plans that are optimal under those assumptions are not optimal when both climate change and technical progress realize.

This paper also explores the nature of the "information effects" of prescribing extraction plans that assume climate, technology, or both are static. The "Law of unintended consequences" is typically cited in political and economic policy circles to highlight the potential of well-intended policies to result in undesired and undesirable outcomes. However, Merton (1936) points-out that undesired is not equal to undesirable. Management plans that are optimal under a specific scenario but sub-optimal in any other realization of the future may still be desirable vis-a-vis non-intervention outcomes. To have a sense of how desirable the unintended consequences of each plan are, the difference between forward looking plans and myopic outcomes is contrasted under different realized scenarios.

\section{Conceptual Framework}

In this section, we develop a stylized dynamic model of groundwater use. Our model in this section is simplified as a linear-quadratic formulation in order to obtain analytical solutions that develop intuition. In the next section, we introduce a more realistic formulation that requires a numerical solution.

Our analytical and numerical models are based on the single-cell framework, which has been a workhorse of the groundwater management literature since its inception (Gisser and Sanchez, 1980; Feinerman and Knapp, 1983). The single-cell model considers an aquifer underlying a flat land surface with vertical sides and holding water that flows laterally at an instantaneous rate so that withdrawals affect the water table height equally in all locations throughout the aquifer regardless of where it is pumped. A large number of users 
of water are assumed to be distributed across the land surface, with identical technology and exogenous prices so that a representative, competitive user can be aggregated to reflect basin-level outcomes.

The single-cell model can be criticized for its strong assumptions about hydrology, which do not accord with the spatial heterogeneity and the slow rates of lateral flow observed in many aquifers (Saak and Peterson, 2012). Recent literature has relaxed the assumptions of instantaneous lateral flow and spatial uniformity (Gaudet et al. 2001, Xabadia et al. 2004, Saak and Peterson 2007, Brozovic et al. 2010, Pfeiffer and Lin 2012, Suter et al. 2012, Guilfoos et al. 2013, Peterson and Saak 2013) to study spatially varying common-pool impacts. However, Brozovic et al. (2010) indicate that the more parsimonious single-cell model may be adequate for small aquifers or a relatively small area within a much larger aquifer, as is the case of interest here. Moreover, our focus is on region-level outcomes as opposed to spatial patterns within the region.

A state variable of the model is the water table elevation, $H$, typically measured in feet above sea leve 2 . The aquifer saturated thickness and well pumping lift can be formulated from the water table elevation as

$$
\begin{aligned}
& S a T=H-H_{c}, \\
& \text { Lift }=S_{L}-H,
\end{aligned}
$$

where $S a T$ is saturated thickness, $H_{c}$ is the elevation of the bottom of the aquifer and $S_{L}$ is the elevation at the surface (i.e., top of the well).

As the aquifer depletes, groundwater is pumped from deeper underground and the value of $H$ decreases. The more groundwater extraction exceeds the net recharge of the aquifer the larger the decrease in water table elevation. The equation of motion for the water table elevation is

$$
\dot{H}=\frac{d H}{d t}=\frac{1}{A_{S}}[r-(1-\alpha) w],
$$

\footnotetext{
${ }^{2}$ For simpler notation, $t$-subscripts are generally omitted from dynamic variables, i.e. $\left(H(t)=H_{t}=H\right)$, but included when needed for clarity.
} 
where $A_{S}$ is the number of acres overlying the aquifer times the specific yield, $r$ is the instantaneous net rate of natural recharge of the aquifer, $\alpha$ is the portion of water applied that returns to the aquifer, and $w$ is the instantaneous rate of groundwater extracted. The initial water table elevation is $H(0)=H_{0}$ and $S_{L}>H>H_{c}$.

The regional net benefits or rents from irrigation is represented by a reward function:

$$
R(w ; \beta, H)=B(w ; \beta)-C(H) w ;
$$

were $w$ is extracted groundwater, $\beta$ is a parameter that determines the marginal value of groundwater, and $H$ is the elevation of the water table in the aquifer and represents the amount of groundwater in the aquifer which declines as $H$ decreases. $B(w ; \beta)$ is the benefit from extracting $w$ units of water and $C(H)$ is the (linear in $H$ ) cost of pumping each acre-foot $(\mathrm{AF})$ of groundwater, where $B^{\prime}(w ; \beta) \geq 0, B^{\prime \prime}(w ; \beta) \leq 0$, and $C^{\prime}(H) \leq 0$. We assume that there are no benefits when there is no irrigation (i.e., $B(0 ; \beta)=0$ ).

Our analysis in this section assumes the reward function is quadratic so that the benefits from irrigation are the area under a linear VMP schedule,

$$
B(w ; \beta)=\int_{0}^{w}(\beta+\gamma u) d u=\beta w+\frac{\gamma}{2} w^{2},
$$

and that the marginal pumping cost function is a linear function of pumping lift, $C(H)=c\left(S_{L}-H\right)$. We also consider the possibility that the marginal value of extracted groundwater may shift over time such that

$$
\dot{\beta}=b_{0}-b_{1} \beta \text {. }
$$

The special case of static VMP, which is implicit in most previous studies, occurs when $b_{0}=b_{1}=0$.

First, consider the outcome of competitive pumping, in which farmers maximize the 
periodic rents from irrigation in myopic fashion. The solution to this optimization results in groundwater extraction in each period such that the value of the marginal product (VMP) of groundwater equals its marginal cost of extraction: $V M P=B^{\prime}(w ; \beta)=C(H)$. When the VMP schedule of groundwater is assumed fixed over time (i.e., fixed $\beta$ ), only the marginal cost of extraction, $C(H)$, changes over time. As the aquifer declines, $H$ decreases and $C(H)$ increases, resulting in a decreasing groundwater extraction path over time. However, when the VMP schedule is allowed to change over time, for instance due to improved technologies or changing climate, both the cost and value of groundwater extraction vary over time and myopic extraction may not be monotonically decreasing over time.

Figure 1a illustrates cases where myopic extraction is increasing between two time periods and figure $1 \mathrm{~b}$ shows the case in which it is decreasing between two time periods. For simplicity, we illustrate the case of a linear VMP schedule. Increasing extraction over time occurs when the increase in the value of groundwater is large relative to the increase in extraction costs at the margin. Decreasing extraction over time occurs when the increase in extraction cost is large relative to the increase in the value of groundwater.

Next, consider the dynamically optimal solution. A planner choosing an extraction path to maximize the net present value of the stream of rents from irrigation would solve:

$$
\max \int_{0}^{\infty} e^{-\rho t}[B(w ; \beta)-C(H) w] d t
$$

subject to (1) and (4). In this specification, the problem is a linear-quadratic control problem with one control variable, $w$, the aquifer state variable $H$, and an exogenous state variable $\beta$. The full problem and its analytical solution are presented in the supplementary appendix. The optimal solution is a linear feedback rule of the form:

$$
w=V+W_{1} \beta+W_{2} H,
$$


where $V, W_{1}$, and $W_{2}$ are coefficients that depend on model parameters. The change in extraction over time may be written as

$$
\dot{w}=W_{1} \dot{\beta}+W_{2} \dot{H}
$$

In the supplementary appendix, we show that the sign of $W_{2}$ is positive. The sign of $W_{1}$ is not unequivocally positive, however. We show in the supplementary appendix that $W_{1}$ is positive for the range of plausible parameters for an aquifer. Only in the cases in which there is both a high discount rate (10 percent or more) and very low expected productivity gains (no more than 10 percent in productivity gains throughout the planning horizon) is the sign of $W_{1}$ negative. The two exceptional conditions of poor gains in productivity and the heavy discounting of future benefits means that groundwater is not (more) valuable in the future. At the extreme of no productivity gains and completely discounted future benefits, the optimal solution would be myopic implying no gains from management are possible.

There is no authoritative reference with respect to potential gains in agricultural productivity into the long-term, but working assumptions employed by USDA (Sands, 2014) foresee increases in productivity between nearly 50 percent (oilseeds) to nearly doubling (coarse grains) by year 2050. The discount rate condition is even more arbitrary; but the discourse in academic and policy circles seems to be more for de-penalizing future benefits by employing lower social discount rates (even zero or negative, in some cases; e.g., Hellweg et al., 2003) than for heavier discounting. Consequently, the available evidence points to scenarios in which groundwater will be more valuable in the future, in which case the sign of $W_{1}$ would be positive.

The positive sign of $W_{2}$ indicates that decreased levels of groundwater stock create an incentive for smaller amounts of groundwater extraction. Similarly, the positive sign of $W_{1}$ indicates that increases in the value of water create an incentive for greater amounts of groundwater extraction. 
A key insight from equation (7) is that extraction may not be monotonically decreasing over time. Intuitively, the term $W_{1} \dot{\beta}$ represents the impact of changes in marginal benefits over time on extraction and the term $W_{2} \dot{H}$ represents the impact of changes in marginal costs over time. If the benefits from irrigation are increasing sufficiently fast, extraction increases over time. Of course, the benefits from irrigation are not likely to continue a rapid increase over an infinite horizon. If marginal benefits increased rapidly until infinity, then extraction is monotonically increasing in the unrealistic case of a bottomless aquifer. In the case of an aquifer with a bottom, then the solution is unstable because there is an incentive to always conserve the water to some future period with greater benefits. Therefore, two extraction paths are most likely .

The first likely path is when marginal benefits increase slowly enough in all periods such that equation (7) is negative and extraction is monotonically decreasing. In the special case of static marginal benefits $(\dot{\beta}=0)$, the extraction path is guaranteed to be monotonically decreasing as in much of the previous literature (e.g. Gisser and Sanchez, 1980; Feinerman and Knapp, 1983; Allen and Gisser, 1984; Pardo et al., 1998; Burness and Brill, 2001; Esteban and Albiac, 2011; Quintana Ashwell and Peterson, 2015; and Esteban and Dinar, 2016). The second likely path is when marginal benefits increase sufficiently fast in early periods and then begins to slow down relative to the increase in costs. In this second case, extraction is increasing in early periods then declines in later periods-effectively creating a peak in groundwater demand.

This stylized model illustrates that dynamically optimal groundwater extraction is not necessarily monotonically decreasing over time and provides an economic intuition on the conditions that result in increasing extraction. However, a limitation of this stylized model is that the linear pumping cost formulation approximates the marginal cost of pumping at the initial lift but it progressively underestimates the marginal cost of pumping over time. As illustrated in figure 1a, a marginal cost of pumping with shifts that are unrealistically slow over time may erroneously prescribe increases in extraction when a more realistic 
formulation results in lower extraction. Similarly, if an increasing path may be optimal over a time lapse, the increasingly underestimated marginal cost of pumping would result in increasing rates of extraction at larger magnitudes over a greater length of time than a more realistic formulation. Furthermore, the linear (in lift) marginal cost of pumping implies an unrealistic bottomless aquifer and a decreasing shadow value of groundwateri.e., its value decreases as it becomes scarcer (Tomini, 2014).

A more realistic formulation would account for nonlinear (with respect to aquifer water levels) increases in pumping costs over time. Unfortunately, no closed-form solutions are possible for such a formulation of the pumping cost function: The model must be solved numerically. The next section describes the numerical solution methods including a nonlinear pumping cost function and details the decomposition of $\beta$ as a function of climate $(\mathrm{CC})$ and technical change (TC) variables to model the shifts in the VMP schedule due to these effects.

\section{Numerical Simulation Model}

Optimal control problems are analytically intractable, except under specific functional forms of the equations of motion and the reward function as in the previous section. In this section, we incorporate declining well yields into the model which makes the pumping cost function nonlinear (Brill and Burness, 1994). One important aspect of incorporating declining well yields is that it effectively places a bottom on the aquifer. Unfortunately, the optimal control problem with declining yields can not be formulated to give analytical solutions. Consequently, we create a discrete numerical simulation model with reasonable parameter values in order to examine the dynamically optimal path of extraction and compare myopic and planned solutions.

The parameter values in the numerical simulation model are obtained or calibrated for Sheridan County, KS, which is a particularly useful region to study. The hydrological and 
agricultural uniformity of the region make the assumptions of a representative user and a single-cell aquifer applicable. The region is also interesting from a policy perspective due to the recent implementation of a farmer-led initiative "Sheridan 6 Local Enhanced Management Area (LEMA6)", which roughly establishes a 20 percent reduction from historical pumping across the area $3^{3}$ The planned allocations presented in this paper are informative for such policies. Another advantage of selecting this region in Kansas is the wealth of agricultural, agronomical, hydrological, and water use data.

\subsection{Hydrology and Pumping Costs}

The hydrologic assumptions of the model are based on the single-cell aquifer framework as summarized by equation (11) in the previous section. However, the cost of pumping is modified here to capture the potentially nonlinear effects of declining groundwater stocks. The cost of pumping depends on the amount of energy used by pumps to deliver groundwater from the water table in the aquifer to the outlet in the irrigation system at a given pressure. The decline in the stock of groundwater available in the aquifer affects the cost of (amount of energy used in) pumping in at least two ways. First, more energy is required to pump each unit of water because it is transported from deeper in the aquifer (i.e., pumping lift $\left(S_{L}-H\right)$ increases). Second, more time is needed to extract a unit of groundwater as well yields - volume of extraction per unit of time - decline. For example, a 50 percent reduction in well yield requires 100 percent more time to pump a given amount of groundwater. We use the well yield function proposed by Sloggett and Mapp (1984): $Y=2 Q_{0} d\left(S a T-\frac{d}{2}\right)=2 Q_{0} d\left(H-H_{c}-\frac{d}{2}\right)$, where $d$ is drawdown and $Q_{0}$ is a constant calculated based on well site characteristics. This function has been previously applied in the economics literature (Brill and Burness, 1994; Burness and Brill, 2001 and Quintana and Peterson, 2015 among others). Combining these two effects, the marginal pumping

\footnotetext{
${ }^{3}$ All farmers were given an allocation of 55 acre-inches per irrigated acre for the period between 2013 and 2017, inclusive.
} 
costs in dollars per acre-foot is

$$
C(H)=\frac{c_{0}}{Y}\left[\frac{S_{L}-H}{S_{L}-H_{0}}\right]=C_{0}\left[\frac{S_{L}-H}{H-H_{c}-\frac{d}{2}}\right],
$$

where $C_{0}=c_{0} /\left(2 Q_{0} d\left(S_{L}-H_{0}\right)\right)$. An important feature of equation $(8)$ is that as the water table reaches the bottom of the aquifer $\left(H \rightarrow H_{c}\right)$, the denominator approaches zero and the marginal cost of pumping approaches infinity. Therefore, the water table never goes lower than the bottom of the aquifer after accounting for the drawdown caused by pumping.

The parameter values for Sheridan County, KS, are summarized in table 1. The parameters in (8) are calculated following Rogers and Alam (2006) such that $C_{0}=0.975$, $S_{L}=2,755, H_{0}=2,644.2 \mathrm{ft} ., Q_{0}=3.48 E-07$, and $H_{c}=2,583.2$. Aquifer initial conditions and parameters were obtained from the Kansas Geological Survey (KGS), the Water Rights Information System (WRIS), and the Water Information Management and Analysis System (WIMAS). At initial conditions, the marginal cost of pumping is $\$ 22$ per acre-foot of groundwater.

\subsection{Climate Change}

Climate change affects both water availability and the demand for water (Doll, 2002). It is multifaceted and spatially heterogeneous: different climate variables change in different directions in different regions. Some regions of the world could face a decline in their water availability while others could see a surplus water supply (Elliott et al., 2014). In the Midwest US, irrigation requirements are expected to increase (Doll, 2002). Projections from USGS's National Climate Change Viewer show that little to no change in average annual precipitation over time. However, the temporal pattern of precipitation is expected to decrease at critical times in the growing season, making irrigation increasingly valuable.

To reflect the changes in the pattern as well as the levels of precipitation within the season, the climate change variables associated with the model are: average precipitation 
between January and April $(J)$, average precipitation between May and August $(M)$ precipitation, and average evapotranspiration from May to August $(E)$. Linear dynamics are devised for these variables following the equations of motion:

$$
\begin{aligned}
\dot{J} & =a_{0}-a_{1} J \\
\dot{M} & =a_{2}-a_{3} M \\
\dot{E} & =a_{4}-a_{5} E .
\end{aligned}
$$

The parameters $a_{0}, a_{1}, \ldots, a_{5}$ are calibrated using values for each of the climate variables at a starting point $(t=0)$, at an intermediate point $(t=1)$, and at the steady state (asymptotic value as $t \rightarrow \infty$ ). Initial values for average January to April $\left(J_{0}\right)$ and May to $\operatorname{August}\left(M_{0}\right)$ precipitation, and for May to August evapotranspiration $\left(E_{0}\right)$ are obtained from Hendricks and Peterson (2012). Terminal (asymptotic steady state) values for these variables are the expected annual average levels projected for the entire period between the years 2075 and 2100 according to the ensemble average projection of the 5th Climate Model Intercomparison Program (CMIP5). Finally, the climate change variables are assumed to change at decreasing rates reaching steady states asymptotically, so the largest changes occur at the beginning. The largest changes in the United States Geological Survey's National Climate Change Viewer (USGS NCCV) are $\dot{J}=0.33, \dot{M}=-0.13$, and $\dot{E}=0.01$. The parameters $a_{0}$ thru $a_{5}$ are found solving a system of 6 equations in 6 unknowns:

$$
\begin{array}{ccc}
J_{\infty}=\frac{a_{0}}{a_{1}}=\bar{J}_{(2075-2100)}, & 0.33=a_{0}-a_{1} J_{0} \\
M_{\infty}=\frac{a_{2}}{a_{3}}=\bar{M}_{(2075-2100)}, & -0.13=a_{2}-a_{3} M_{0} \\
E_{\infty}=\frac{a_{4}}{a_{5}}=\bar{E}_{(2075-2100)}, & 0.01=a_{4}-a_{5} E_{0} .
\end{array}
$$

The initial value for the variables and the calculated value for the parameters in equations (9) to (11) are reported in table 1. Notice that the value of these variables at 
time $t$ are easily calculated as

$$
\begin{aligned}
J(t) & =\frac{a_{0}}{a_{1}}+\left(J_{0}-\frac{a_{0}}{a_{1}}\right) e^{-a_{1}(t-1)} \\
M(t) & =\frac{a_{2}}{a_{3}}+\left(M_{0}-\frac{a_{2}}{a_{3}}\right) e^{-a_{3}(t-1)} \\
E(t) & =\frac{a_{4}}{a_{5}}+\left(E_{0}-\frac{a_{4}}{a_{5}}\right) e^{-a_{5}(t-1)}
\end{aligned}
$$

where $t$ can be in continuous or discrete time.

\subsection{Technical Change and Groundwater Demand}

Although advances in agricultural biotechnology, equipment, and machinery may occur in response to market signals, these occur at aggregation levels that are distant from the relevant decision unit: the irrigator. Consequently, such technical changes are exogenous to farmers.

Technical change may occur in diverse ways. Advances in biotechnology may result in one or several of the following changes: (i) crop wilting points may be reduced; (ii) fully-watered yields may be increased; (iii) potential evapotranspiration may decrease or increase; or (iv) the shape of the yield water response functions may change. Advances in equipment, machinery, and farming practices may result in improved precipitation effectiveness or improved application efficiency. All these changes modify the incentives of farmers to pump groundwater.

In this paper, technical progress is modeled as shifts in a linear groundwater (inverse) demand function that is conditional on climate conditions and where the intercept term represents the state of technology:

$$
p^{w}\left(w ; \beta_{0}, J, M, E\right)=\beta_{0}-\beta_{1} J-\beta_{2} M+\beta_{3} E-\beta_{4} w
$$

where $w$ is groundwater pumping, $\beta_{0}$ is the intercept representing the state of technology, 
$J$ is average daily precipitation between January and April, $M$ is average daily

precipitation between May and August, and $E$ is evapotranspiration between May and

August. The coefficients for $J, M$, and $E$ are calculated and rescaled from Hendricks and

Peterson (2012). The demand function in equation (14) is consistent with a quadratic

production function for a composite irrigated crop that depends on the volume of irrigation water applied. Quadratic crop yield response to irrigation is consistent with the agronomic literature that relates crop yields to irrigation application (Martin et al. 1984).

Climate change affects water demand by allowing $J, M$, and $E$ to enter as dynamic parameters that shift the (inverse) demand curve for groundwater. Technical change affects water demand through upward shifts in the VMP schedule by increasing $\beta_{0}$ over time. The equation of motion for the intercept is specified as a linear approximation of the rate of technical progress:

$$
\dot{\beta}_{0}=b_{0}-b_{1} \beta_{0}
$$

The initial value for $\beta_{0}$ is calculated residually from the intercept term in the (inverse) groundwater demand equation $\left(\beta_{0}(0)=232.67\right)$. The terminal value is established to reflect an assumption of water productivity asymptotically reaching a level twice ${ }^{4}$ its initial value:

$$
\beta_{\infty}=\frac{b_{0}}{b_{1}}=2 \beta_{0}
$$

Finally, to calculate the technical change parameter, $b_{0}$ and $b_{1}$, a 1.1 percent increase in productivity is assumed on the initial period. This productivity increase is consistent with what Quintana and Featherstone (2015) found for a sample of Kansas farms over the

\footnotetext{
${ }^{4}$ References on productivity ceilings are not easy to find in the literature. The productivity parameter ceiling of twice its initial value is somewhat arbitrary but based on Monsanto's stated goal of doubling yields of corn and other crops by year 2030 (Edgerton, 2009). Most studies found on the topic of productivity increase focus on yield trends suggesting average rates of productivity increases but few provide insight into the decreasing rates of the increases ( Ewert et al., 2005, presents data showing the decreasing growth of productivity gains over time).
} 
period 1993 to 2011. The time path for the technical change parameter is described by:

$$
\beta_{0}(t)=\frac{b_{0}}{b_{1}}+\left(\beta_{0}(0)-\frac{b_{0}}{b_{1}}\right) e^{-b_{1}(t-1)}
$$

\subsection{Groundwater Extraction under Myopic and Alternative Planning Scenarios}

The difference in periodic groundwater allocations between myopic and planned scenarios reflects the main societal trade-off between current versus future food production. In this context, net farm benefits are a good approximation for social welfare (Quintana and Peterson, 2015).

The rents from irrigation function is the area under the inverse groundwater demand curve minus the cost of extraction and represents the profits in addition to what can be achieved from dryland rather than actual farm profits. The periodic rent function for irrigation is expressed as

$$
R\left(w ; \beta_{0}, J, M, E, H\right)=\left[\beta_{0}-\beta_{1} J-\beta_{2} M+\beta_{3} E-\frac{1}{2} \beta_{4} w-C_{0}\left[\frac{S_{L}-H}{H-H_{c}-\frac{d}{2}}\right]\right] w .
$$

Given the state of the climate, technology, and the aquifer $\left(\beta_{0}, J, M, E, H\right)$, the myopic allocation is determined by first order conditions on the rent function:

$$
\frac{\partial R(w ; \cdot)}{\partial w}=\beta_{0}-\beta_{1} J-\beta_{2} M+\beta_{3} E-\beta_{4} w-C_{0}\left[\frac{S_{L}-H}{H-H_{c}-\frac{d}{2}}\right]=0 .
$$

In contrast, the optimal plan accounts for all state variables and maximizes the net present value of the stream of rents from irrigation

$$
N P V=\max \sum_{t=0}^{T}\left(\frac{1}{1+\rho}\right)^{t} R\left(w(t) ; \beta_{0}(t), J(t), M(t), E(t), H(t), t\right)
$$


subject to the equations of motion $(13),(16)$, and the discrete approximation of (1):

$$
H_{t+1}-H_{t}=\frac{1}{A_{S}}\left[r-(1-\alpha) w_{t}\right]
$$

where $w_{t}$ is the total amount of groundwater extracted in period $t$, as opposed to the instantaneous rate implied in equation (1). Similarly, the rate of recharge in this equation is in acre-feet per year $\left(\mathrm{AF} / \mathrm{yr}\right.$, see table 1). The discount rate $5^{5}$ considered, $\rho=0.0389$, is the average interest rate on farm loans as reported from the Kansas City Federal Reserve Bank (November, 2011).

We consider four alternative plans of groundwater extraction. Each of the plans achieves the highest gains from management for the scenario it assumes . The first plan accounts for changes in water table height, climate and technology and is labeled "Baseline." The second plan, labeled "No TC", assumes there is no technical change: $\beta_{0}(t)=\beta_{0}(0), \forall t$. The third plan assumes climate change does not realize (i.e., $\left.J(t)=J_{0}, M(t)=M_{0}, E(t)=E_{0}, \forall t\right)$, and is labeled "No CC." The last plan is labeled "No CC or TC" and considers only the aquifer dynamics with the assumption that neither climate nor technical change realize, i.e., the right-hand side of equations (9) through (11) and 15 equal zero.

By solving for different planned solutions, this paper is able to assess the "information effects" of prescribing a groundwater extraction plan without accounting for important dynamic factors that influence the incentives at play in irrigated agriculture. Each plan is the best for the state of the world it assumes. However, by comparing across the solutions we can assess the information effects of plans that are formulated with assumptions that turn out to be incorrect. For example, we can assess the risks, in welfare terms, of developing plans and implementing policies that assume no climate change or technical change, when in fact those changes are realized. Similarly, we can assess the risk of

\footnotetext{
${ }^{5}$ There is a growing literature that deals with the question of how future outcomes should be discounted. A discussion of the topic is beyond the scope of this paper but a good one is available in Gollier and Hammitt (2014). In any case the 3.89 percent rate used here is within the range employed in the literature.
} 
implementing policies based on plans that do assume climate change or technical change, when in fact those changes do not occur as expected.

The NPV of the stream of benefits under each planning scenario under alternative realizations is calculated (i) when both technical change and climate change occur, (ii) when only technical change occurs, (iii) when only climate change occurs, and (iv) when demand is static. The outcomes indicate the loss in welfare from an incorrect plan that ignores a dynamic aspect of demand that should have been considered or accounts for a dynamic aspect of demand that does not actually occur.

The effects of climate change and technical change on the aquifer become apparent when comparing aquifer outcomes (water table elevation, pumping lift, saturated thickness) over time. Because conservation is not a goal in the optimization problem it is not necessarily expected that the optimal plan will result in an aquifer depleted to a lesser degree. Actually, because what is being maximized is the net present value of the rents from irrigation (NPVs), it is not even the case that periodic rents in the steady state would be higher under the optimal plan.

\section{Results}

The optimization problem in 19 is solved with a quasi-newton algorithm in MatLab ${ }^{\circledR}$. The states of climate and technology are calculated from equations $(13)$ and $(16)$ for $t=0,1, \ldots, T$. The control variable $\mathbf{w}$ is a vector of size $T+1$ for which the entries correspond to periodic groundwater extractions. The elements of a vector $\mathbf{h}$ represent the water table elevation for each period and is calculated from each element in w. With each trial value of $\mathbf{w}$, the values of $\mathbf{h}$ and the NPV of stream of rents is updated. Outcomes under several planing horizons were compared ( $T=200,500,700,1000,10000)$ yielding insignificant differences in path and NPV amounts between horizons of more than 500 periods. Results from $T=500$ are reported unless otherwise indicated. 


\subsection{Groundwater extraction and depletion}

Figure 2 shows the time path of groundwater extraction prescribed under each plan. The "No $C C$ or $T C$ " plan has a strictly decreasing trajectory because it considers only one state variable: the stock of groundwater, which drives pumping costs upward as the stock diminishes. All other plans and the myopic outcome exhibit periods of increasing rates of extraction induced by the increasing benefits of groundwater extraction from technical change or climate change. In particular, groundwater extraction reaches the highest peak in period 23 of the "Baseline" plan. The shape of the extraction path for all of these plans are consistent with equation (7) in section 2 and the intuition from figure 1: a monotonic path for plans considering a single state and a (possibly) non-monotonic path for plans incorporating more than one state variable.

Although periodic groundwater allocations differ across plans, all forward-looking plans prescribe lower rates of extraction than the myopic case for the first 37 periods of simulation. This translates into more saturated thickness under the forward-looking plansi.e., groundwater conservation. Figure 3 shows the corresponding saturated thickness of the aquifer over time.

Notice in figure 2 that the "Baseline" plan prescribes the lowest rates of initial rates of extraction (i.e., groundwater conservation corresponding to a 20 percent reduction from the starting point of the myopic trajectory ${ }^{6}$ ) but also allows to reach the highest peak of extraction among the forward-looking plans. The differences in extraction between the "Baseline" and the other forward-looking plans is relatively large while the difference between the "No TC" and "No CC" plans is relatively small.

\footnotetext{
${ }^{6}$ Prior to the establishment of Sheridan County's Local Enhancement Management Area (LEMA), average groundwater use was 13.18 acre-inches (AI) per year. The LEMA established a limit of 55 AI over a five year period, i.e. an average of 11 AI per year; which is a reduction of approximately 17 percent in initial extraction rates.
} 


\subsection{Gains under realized climate and technical change}

Figure 4 depicts the path of realized rents from the different plans, assuming that climate and technology change over time as expected in the baseline case. The rents from irrigation are calculated from the periodic reward function and all the state variables are allowed to update even in the outcomes where one or more of the state variables were ignored in the planning process. That is, extraction occurs in the amount prescribed by each plan but the profits from that prescription are derived from updated technology and climate. The myopic outcomes are obtained from static periodic optimization considering the updated state variables for each period.

As expected, there are significant differences in the periodic rents between each of the plans and the myopic outcome (figure 44). The periodic rents from irrigation capture the "information effects" of prescribing allocations from plans that consider different information sets regarding state dynamics. Periodic rents under myopic pumping are slightly larger than any of the plans for the first 25 periods but decline precipitously thereafter and myopic rents are lower than any of the plans by period 30. The paths of groundwater extraction and rents from irrigation have similar patterns but the difference in relative magnitudes among the different plans is much larger with respect to groundwater extraction. Another interesting feature is that planned peak groundwater extraction (around period 25) precedes planned peak groundwater rents (near period 40).

Notice also in figure 4 that future rents from the alternative plans (not the "Baseline") yield rents consistently higher than the "Baseline" and myopic plans from period 50 onward. However, if the goal is to maximize the stream of discounted benefits rather than to conserve groundwater, then the problem is to identify the best path for decline. In this paper the optimal path is determined by the maximization of the NPV of rents from irrigation over the life of the resource which in this formulation reaches a steady state within the first one hundred periods.

A salient result from the simulations is that the myopic scenario reaches a steady state 
much quicker than any of the forward-looking management plans because aquifer depletion also occurs at a faster rate. The implication of this result is that the "option value" of having a reserve stock of water is also eliminated in a relatively early stage. This means that the ability to alleviate the effects of extreme weather or market conditions is essentially forfeited early on under the myopic regime.

Table 2 compiles the net present value of the rents from irrigation (NPV), the potential gains from management, the cumulative groundwater extraction, and the amounts of water potentially saved under each alternative plan for the first two hundred periods of simulation.

The "Baseline" extraction plan yields the highest NPV of cumulative rents at $\$ 685$ million while the myopic outcome accumulates the lowest NPV of rents at $\$ 529$ million. The alternative plans, i.e. "No $T C$ ", "No CC" and "No CC or $T C$ "; yield accumulated NPVs of $\$ 681$ million, $\$ 679$ million, and $\$ 659$ million respectively. All the forward-looking groundwater management plans yield significant potential gains from management for the first 200 periods of simulation. The optimal plan yields the highest gains at 29.5 percent larger NPV than the myopic case. The "No $T C$ " plan yields 28.8 percent gains from management. The "No $C C$ " plan yields 28.4 percent gains and the "No $C C$ or $T C$ " plan yields 24.6 percent in potential NPV of rent gains from managing the aquifer.

Cumulative extraction over the first 200 periods was as high as 10.16 million acre-feet for the myopic plan and as low as 9.37 million acre-feet (a 7.8 percent groundwater savings relative to the myopic outcome) for the "No CC or TC" plan. The "Baseline" plan prescribed the largest amount of groundwater extraction among the planned outcomes at 9.86 million acre-feet resulting in water savings of 2.9 percent compared to the myopic outcomes. The "No TC" and "No CC" plans extracted 9.78 and 9.66 million acre-feet representing savings of 3.8 and 4.9 percent from to the myopic case, respectively.

The contrast between cumulative NPVs and cumulative groundwater extraction highlights the implicit trade-off involved in the formulation of a groundwater management 
plan. If the extraction from the "Baseline" plan is implemented and becomes the basis of comparison, the results from table 2 can be conversely read as the costs in foregone rents to obtain savings in groundwater-i.e., conservation. For instance, following the "No CC or $T C$ " plan would save $494,600 \mathrm{AF}(=9,863.5 k A F-9,368.9 k A F)$ or $5.014 \%$ of the "Baseline" extraction and cost $\$ 25.79(=685.130-659.338)$ millions or $3.7 \%$ of "Baseline" profits. Based on similar calculations, the "No $T C$ " plan saves 0.88 percent of extracted groundwater with 0.5 percent foregone rents; and the " $N o C C$ " plan saves 2.03 percent of groundwater at a cost of 0.82 percent of foregone rents.

\subsection{Cost of no management vs. cost of incomplete information}

An extraction plan drawn with specific paths for technical and climate changes that do not realize would be costly. In that sense, the downside risk of prescribing an extraction plan expecting climate and technical change is the potential relative cost of a plan that is suboptimal in the alternative scenario that is realized.

Table 3 summarizes the gains from management for each plan evaluated under different realized scenarios. The first column replicates the gains from management in table 2 . The remaining columns show results when technical change or climate change do not actually occur. The gains from management for each plan in each of the realized scenarios (the columns) is calculated in three steps. First, the periodic groundwater extraction under each plan is valued to the present using the value function and the periodic realizations of the different state variables. Second, myopic outcomes are calculated for each of the realized scenarios, including groundwater extraction and the associated present value of the net benefits. Finally, the value of each plan is compared to the value of the myopic outcome for each of the realized scenarios. In each case, the plan that correctly accounts for the realized scenario results in the highest gains from management.

The differences between best and worst plans under each realized scenario are a measure of the cost of implementing an imperfect plan. The greatest such difference is found in the 
last column of the table (when neither technical change nor climate change occurs), between the "Baseline" and the "No CC or TC" plans. The gains from these plans differ by nearly $\$ 18$ million, or $5.2 \%(=6.1 \%-0.9 \%)$ of myopic NPV. Thus, the worst outcome for an imperfect plan - i.e., the largest "downside" risk - results when extraction follows the "Baseline" plan but neither climate nor technical change actually occur.

In contrast, the smallest difference occurs when there is no climate change but technical progress actually occurs (next-to-last column), and is the $1.5 \%(=21.5 \%-20.0 \%)$ difference between the "Baseline" and "No CC" plans. In the state of the world with technical change and no climate change, all plans perform similarly. The performance gaps are intermediate between these two extremes in the remaining columns.

Even in this worst case with the largest costs from an erroneous plan, the "Baseline" plan is still preferred to the unregulated myopic outcome. In fact, gains of $0.9 \%$ are much larger than the typical GSE outcome. Nevertheless, if there are transaction costs to policy intervention, the gains from management may vanish. If the prevalent belief is that groundwater will not be more valuable in the future, it would be tempting to not advocate for improved allocation over time because little to no real gains may be achieved in practice and focus instead on developing institutions to optimize allocation among different -valuable- uses (Gisser, 1983).

In contrast, the gains from management when climate or technical change occur are much larger than when demand is static, achieving 20 to 30 percent gains depending on the plan implemented and the scenario realized. The first three columns in table 3 show that not having a management plan can cost about 30 percent in foregone profits when groundwater becomes more valuable over time, for instance due to climate or technical change as is the case in this example. Similarly, the cost of intervening but doing so incorrectly, i.e. having the "wrong plan" for the realized scenario, is modest with at most 5 percent in potential gains foregone vis-a-vis the optimal plan for that scenario. In sum, no-management is more costly than management with incomplete information. 


\subsection{Effects of alternative scenarios}

As described in the previous sections, the model is parameterized to reflect initial conditions descriptive of Sheridan County, Kansas. This section presents the results of alternative initial aquifer conditions and alternative climate change scenarios. The exercise serves two purposes: it serves as a robustness check and it allows an assessment of how different changes in climate change scenarios and aquifer conditions - perhaps similar to conditions in other regions - affect the optimal paths and potential gains from management. Each of the alternative initial aquifer conditions scenarios are evaluated under the same climate and technical change as the "Baseline" case. By contrast, the alternative climate change scenarios "Slower CC", "Slower TC", and "Slower CC \& TC" scenarios assume the same aquifer conditions as the "Baseline" but changes in climate and technology occur as described below. The shape of the resulting groundwater extraction paths shown in figure 5 are consistent with the intuition gained from section 2 under a variety of alternative parameter values and climate and technical change scenarios.

Figures 5 and 6 show how the "Baseline" extraction plan compares to the optimal extraction paths when alternative initial conditions are considered. Starting with figure 5 . the first alteration in initial conditions, "+20\% Lift" reflects an increase of 20 percent in the initial pumping energy cost (equivalent to a 20 percent increase in initial pumping lift), all else equal. The second alternative initial condition, "+20\% Sat.thick." illustrates the case in which 20 percent higher saturated thickness is initially observed. The " $+20 \%$ Net rech." is the optimal plan when the initial rate of natural recharge is 20 percent higher than observed.

The alternative climate and technical change scenarios consist in halving the rates $\sqrt{7}$ considered in the "Baseline" simulation. "Slower $C C$ ", represents the optimal plan when

\footnotetext{
${ }^{7}$ The periodic climate and technical parameters are given by: $\beta_{0}(t)=\frac{b_{0}}{b_{1}}+\left(\beta_{0}(0)-\frac{b_{0}}{b_{1}}\right) e^{-\mathbf{0 . 5} b_{1}(t-1)}$, $J(t)=\frac{a_{0}}{a_{1}}+\left(J(0)-\frac{a_{0}}{a_{1}}\right) e^{-0.5 a_{1}(t-1)}, M(t)=\frac{a_{2}}{a_{3}}+\left(M(0)-\frac{a_{2}}{a_{3}}\right) e^{-0.5 a_{3}(t-1)}$, and $E(t)=\frac{a_{4}}{a_{5}}+$ $\left(E(0)-\frac{a_{4}}{a_{5}}\right) e^{-\mathbf{0 . 5} a_{5}(t-1)}$.
} 
climate change occurs at half the pace originally considered. "Slower $T C$ ", represents the optimal plan when technical change occurs at half the pace originally considered. "Slower $C C \& T C$ ", represents the optimal plan when both climate and technical change occurs at half the pace originally considered.

The outcomes with respect welfare gains, approximated by the net present value of the stream of irrigator rents, are presented in table 4 . Increased lift, slower change, and high discount rates decrease the potential gains from management. The intuition behind the effect of high discount rates is straight forward: it vanishes any future gains by discounting future rents towards zero giving larger weight to rents earned earlier in the planning horizon. The effect of increased initial lift is that pumping cost increases quicker than in other scenarios thus drastically reducing the net present value of future rents. Finally, slower change implies that the value marginal product of groundwater increases at a lower pace which reduces value of future rents in a manner similar to higher discount rates but differing from it in that it also makes the paths flatter (recall that non-static demand drives the hump shape).

By contrast, a greater saturated thickness, higher net recharge, higher demand elasticity, and lower discount rate have the effect of increasing the potential gains from management. Lower discount rates assign higher importance to rents achieved in the future so earlier groundwater savings are not as costly in terms of NPV and can be translated into higher returns in the future when groundwater is more valuable. Higher demand elasticity makes the planner more sensitive to the nonlinear increases in pumping costs as the aquifer depletes, thus inducing larger earlier savings and extraction peaks. Greater saturated thickness and higher net recharge essentially allow for a larger amount of the resource to be managed and clearly contrasts what is observed with the higher lift scenario.

All plans, except the case with higher net recharge rate, reach the same steady state asymptoticallly. The case where a higher rate of recharge is considered allows for higher levels of sustainable groundwater pumping. A feature in the narrative opposing (regulated) 
groundwater management is that scarcity can be dealt with when it actually becomes a problem at the field level. However, the results indicate that waiting might be costly in terms of potential gains from management because the potential gains are reduced when lift increases and saturated thickness decreases.

The faster aquifer decline under the myopic outcomes reduces the stocks of groundwater to be allocated over time. The substantially lower initial levels of extraction in the plan that considers a higher lift scenario, in addition to a substantial reduction in the potential gains from management, indicates that a higher lift scenario results in greater reductions in benefits in the initial periods and less discounted net benefits over the long run.

\section{Conclusions}

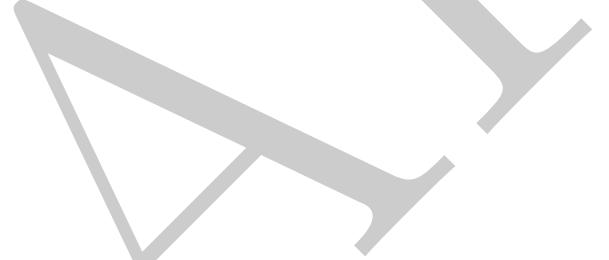

This paper presents a framework to study the combined and individual effects of technical change and climate change on groundwater extraction, the resulting aquifer decline, and the expected rents from irrigation. The context of the study is a declining aquifer where groundwater well yields decrease with the amount of groundwater stored and groundwater demand is nonstatic due to climate and technical change. The problem is formulated as a nonlinear optimal control problem where groundwater extraction is the control variable and the elevation of the water table represents the state of the aquifer. The climate and technical variables evolve exogenously while the aquifer variable is periodically affected by groundwater extraction but not directly by the other state variables.

Four forward-looking extraction plans and one myopic extraction regime are simulated. The forward looking plans are computed by maximizing the net present value of the sum of the periodic rents from irrigation over the life of the aquifer while the myopic regime is computed as periodic rent optimization based on first order conditions and periodic realizations of the state variable. The Baseline plan has perfect foresight of the future realization of all state variables accounted for in that optimization. The remaining plans 
ignore or omit future realizations of climate change, technical progress, or both type of variables in prescribing the respective extraction paths.

The parameters in the model reflect agronomical and hydrological conditions in Sheridan County, KS and linear dynamics for technical and climate change are calibrated. Climate change variables include periodic average precipitation between January and April $(J)$, periodic average precipitation between May and August $(M)$, and periodic average evapotranspiration between May and August ( $E$, alfalfa-based). A widely used formulation of the aquifer dynamics is employed to update the elevation of the water table in the aquifer.

The numerical results indicate that the predicted gains from management are only 6.1 percent of the discounted stream of rents from myopic extraction if the plan assumes that neither climate nor technical change occurs and these assumptions turn out to be correct. This result accords with much of the previous literature and could be cited as a rationale for opposing any intervention to manage groundwater extraction (Gisser, 1983). However, once we account for plausible changes in marginal benefits over time through technical change and climate change, the predicted gains from management are between 20 and 30 percent of myopic rents when climate or technical change actually occur. This result provides a strong rationale for groundwater management. Furthermore, our results indicate that the gains from management are still large if technical change or climate change are realized even if the plan ignores the dynamics of these factors. In fact, any forward-looking plan fares better than the myopic regime in terms of cumulative net present value of rents from irrigation.

All regimes considering technical or climate change allow for periods in which groundwater pumping is increasing. However, all forward-looking plans suggest that an immediate decrease from the myopic levels of extraction is necessary. The Baseline plan mandates the greatest initial decrease in pumping rate or greatest initial groundwater savings. The periods of increasing pumping rates are driven by the increasing productivity 
of groundwater (technical progress) and the increasing net irrigation requirements induced by climate change (changing precipitation patterns and increasing evapotranspirative needs).

Increased rates of extraction correspond to higher levels of periodic rents from irrigation so that faster decline and higher profitability could be expected in the next several periods of plan implementation. However, disregarding the net present value logic of the

optimization, the periodic rents in the long run are greatest for the most conservative plans because these have the smallest pumping lifts in the steady-state which result in the lowest pumping costs in the long run.

When the optimal path of extraction is determined by the maximization of the net present value of the rents from irrigation, relatively large groundwater savings may be achieved at relatively small foregone profits. However, when limited alternative (valuable) uses are available for the resource, maximization of the NPV of cumulative rents seems to be an adequate plan evaluation metric and the question that remains is how to discount the future which is beyond the scope of this paper.

The optimality of a future peak groundwater extraction results from the non-static groundwater demand in the formulation. The shifts in groundwater demand are consistent with the notion that groundwater will be more valuable in the future. Two plausible avenues for how these shifts may occur are via changes in climate and technical progress. By including exogenous state variables (climate and technology) in addition to the aquifer state variable, this paper allows for a wider range of possible optimal paths for the aquifer eliminating the limitation of single-state formulation which force monotonic state paths. Because such demand shifts are almost certain to occur and because they induce paths that differ from the results of conventional one-state and static groundwater demand models, the inclusion of multiple state variables and non-static groundwater demand should be the norm, not the exception, in studies of optimal dynamic extraction of groundwater.

The rapid aquifer decline under the myopic outcomes and the results under alternative 
planning scenarios suggest that delaying the implementation of groundwater management plans may diminish the potential management gains achievable. Whether this should be an argument for conservation or not is not discussed in this paper, but savings may be achieved at the cost of relatively low foregone rents.

The contrast between the myopic and optimal extraction paths indicate that it is optimal to prescribe significant groundwater pumping restrictions - on the order of 20 percent - at the beginning of the planning horizon and to allow increased rates of groundwater extraction in later periods when groundwater is more valuable. Consequently, it should not be surprising if groundwater managers (of well managed resources) allow future increases in maximum groundwater extraction in areas where restrictive groundwater management policies exist, such as in Sheridan County, KS.

The formulation in this article employs private benefits as a proxy for social welfare. This is an adequate formulation for cases in which there is little regional competition for the resource among other uses such as industrial or municipal. Furthermore, the formulation implicitly assumes that little interactions exist between the stocks of groundwater in the aquifer and surface waters and ecosystems. The formulation adequately describes the study area in Western Kansas to which it is applied. However, when circumstances merit significant impact on aquifer viability, ecosystems health, and availability to other competing uses, these aspects must be incorporated in the modeling. Given the strong rationale for conservation presented in this paper, it seems like the consideration of such environmental aspects would further strengthen, rather than negate, the main results from this paper.

Another caveat in our model is the assumption of a fixed rate of net natural recharge. Climate change can be expected to impact aquifer recharge. The growing literature on the subject would greatly benefit from increased attention from economists. The assumption of a fixed recharge rate in this paper is more palatable because we model a change in annual precipitation patterns in an area were annual mean precipitation is projected to have little 
to no change.

Finally, uncertainty or disbelief about climate change is an often raised objection to managing natural resources. The numerical analysis shows that the downside risk of accounting for changes in climate and technical progress that do not materialize is small. Although gains from management would be reduced, returns are still better than the myopic outcomes.

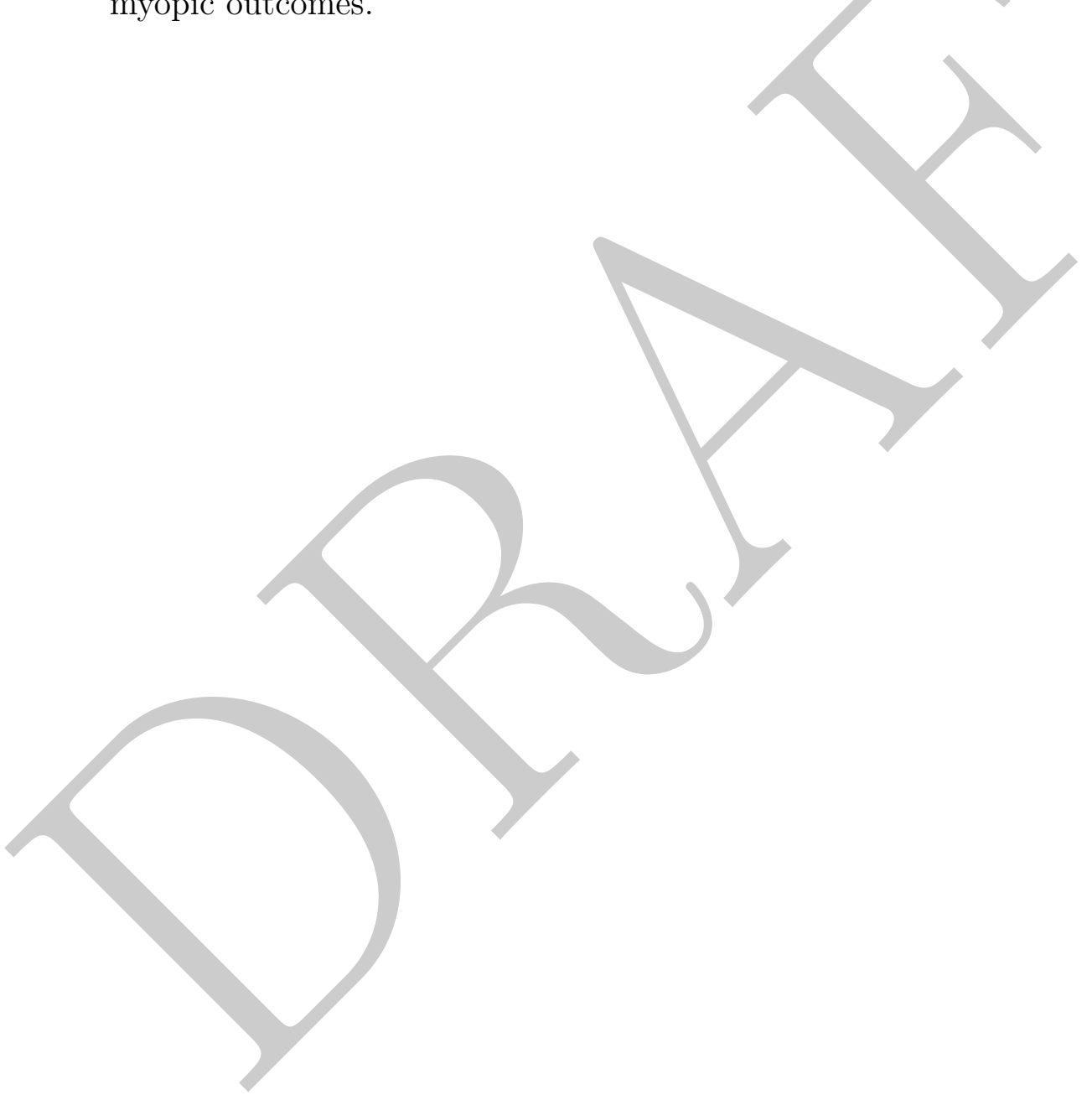




\section{References}

[1] Allen, R.C. and Gisser, M. Competition versus optimal control in groundwater pumping when demand is nonlinear. Water Resources Research, 1984, 20(7): $752-756$.

[2] Brill,T.C. , and H.S. Burness, Planning versus competitive rates of groundwater pumping, Water Resources Research, 1994, 30(6): 1873-1880.

[3] Brozovic, N., D. L. Sunding, and D. Zilberman, On the spatial nature of the groundwater pumping externality, Resource and Energy Economics,2010, 32(2), 154-164.

[4] Burness, H.S., and T.C. Brill, The role for policy in common pool groundwater use, Resource and Energy Economics , 2001,23: 19-40.

[5] de Frutos Cachorro, J., Erdlenbruch, K. and Tidball, M., 2014. Optimal adaptation strategies to face shocks on groundwater resources. Journal of Economic Dynamics and Control, 40, pp.134-153.

[6] Doll P. Impact of climate change and variability on irrigation requirements: a global perspective. Climatic change. 2002 Aug 1; 54(3):269-93.

[7] Edgerton, M.D. Increasing crop productivity to meet global needs for feed, food, and fuel. Plant physiology 149, no. 1 (2009): 7-13.

[8] Elliott, J., Deryng, D., Muller, C., Frieler, K., Konzmann, M., Gerten, D., Glotter, M., Florke, M., Wada, Y., Best, N. and Eisner, S., 2014. Constraints and potentials of future irrigation water availability on agricultural production under climate change. Proceedings of the National Academy of Sciences, 111(9), pp.3239-3244.

[9] Esteban, E., and J. Albiac. Groundwater and ecosystems damages: Questioning the GisserSanchez effect. Ecological Economics 70.11 (2011): 2062-2069. 
[10] Esteban, E. and Dinar, A., 2016. THE ROLE OF GROUNDWATERDEPENDENT ECOSYSTEMS IN GROUNDWATER MANAGEMENT. Natural Resource Modeling, 29(1), pp.98-129.

[11] Ewert, F., M. D. A. Rounsevell, I. Reginster, M. J. Metzger, and R. Leemans. Future scenarios of European agricultural land use: 1. Estimating changes in crop productivity. Agriculture, Ecosystems \& Environment 107, no. 2 (2005): 101-116.

[12] Feinerman, Eli, and Keith C. Knapp. Benefits from Groundwater Management: Magnitude, Sensitivity, and Distribution. American Journal of Agricultural Economics 65, no. 4 (1983): 703-10.

[13] Gaudet, G., M. Moreaux, and S.W. Salant. Intertemporal depletion of resource sites by spatially distributed users. The American Economic Review 91, no. 4 (2001): 1149-1159.

[14] Gisser, Micha. Groundwater: focusing on the real issue. The Journal of Political Economy (1983): 1001-1027.

[15] Gisser, M and D.A. Sanchez, Competition versus optimal control in groundwater pumping, Water Resources Research, 16 (4): 638-642, 1980.

[16] Gollier, C. and J. K. Hammitt, The Long-Run Discount Rate Controversy, Annu. Rev. Resour. Econ., 6(1), 273-295, 2014.

[17] Guilfoos, T., Pape, A.D., Khanna, N. and Salvage, K. Groundwater management: The effect of water flows on welfare gains. Ecological Economics 95 (2013): 31-40.

[18] Hellweg, S., T. B. Hofstetter, and K. Hungerbuhler. Discounting and the environment should current impacts be weighted differently than impacts harming future generations? The International Journal of Life Cycle Assessment 8, no. 1 (2003): 8-18. 
[19] Hendricks, N.P., and J.M. Peterson. Fixed effects estimation of the intensive and extensive margins of irrigation water demand. Journal of Agricultural and Resource Economics, 2012, 37(1):1-19.

[20] Kansas Geological Survey, An Atlas of the Kansas High Plains Aquifer,2000.

[21] Kansas Geological Survey, Calculation of Yield for High Plains Wells: relationship between saturated thickness and well yield, 2000.

[22] Kim, C.S., Moore, M.R., Hanchar, J.J. and Nieswiadomy, M., 1989. A dynamic model of adaptation to resource depletion: theory and an application to groundwater mining. Journal of Environmental Economics and Management, 17(1), pp.66-82.

[23] Koundouri, P. (2004), Potential for groundwater management: Gisser-Sanchez effect reconsidered. Water Resources Research, 40, W06S16, doi:10.1029/2003WR002164.

[24] Leonard, Daniel, and Ngo Van Long. Optimal control theory and static optimization in economics. Cambridge University Press, 1992.

[25] Martin, D. L., D. G. Watts, and J. R. Gilley (1984). Model and production function for irrigation management. Journal of irrigation and drainage engineering, 110(2), 149-164.

[26] Merton, R.K., 1936. The unanticipated consequences of purposive social action. American sociological review, 1(6), pp.894-904.

[27] Negri, Donald H. The common property aquifer as a differential game. Water Resources Research 25.1 (1989): 9-15.

[28] Nieswiadomy, Michael. The demand for irrigation water in the High Plains of Texas, 195780. American Journal of Agricultural Economics 67.3 (1985): 619-626. 
[29] Pardo, F. J., C. Martinez, and J. P. Castro. Gestion optima de aguas subterraneas. Revista espanola de economia 15.1 (1998): 085-121.

[30] Peterson, J.M. and Bernardo, D.J., 2003. High Plains regional aquifer study revisited: a 20-year retrospective for western Kansas. Great Plains Research, pp.179-197.

[31] Peterson, Jeffrey M., and Alexander E. Saak. Spatial externalities in aquifers with varying thickness: Theory and numerical results for the Ogallala aquifer. In 2013 Annual Meeting, August 4-6, 2013, Washington, DC, no. 150553. Agricultural and Applied Economics Association, 2013.

[32] Pfeiffer,L, and C. Lin, Does efficient irrigation technology lead to reduced groundwater extraction? Empirical evidence., Journal of Environmental Economics and Management, 2014, 67(2):189-208.

[33] Pulido-Velazquez, M., Andreu, J., Sahuquillo, A. and Pulido-Velazquez, D., 2008. Hydro-economic river basin modelling: The application of a holistic surfacegroundwater model to assess opportunity costs of water use in Spain. Ecological Economics, 66(1), pp.51-65.

[34] Quintana-Ashwell, N.E. and A.M. Featherstone, Beyond benchmarks: DEA study of Kansas Farm Productivity, 2015 Annual Meeting, January 31-February 3, 2015, Atlanta, Georgia. No. 196857. Southern Agricultural Economics Association.

[35] Quintana-Ashwell, N.E. and J.M. Peterson, The Impact of irrigation Capital Subsidies on Common-pool Groundwater Use and Depletion: Results for Western Kansas.Water Economics and Policy (2015):1550004.

[36] Rogers, D.H., and M. Alam, Comparing irrigation energy costs, Kansas State University Agricultural Experiment Station and Cooperative Extension Service, Extension Bulletins, Irrigation Management Series, MF-2360, August 2006. 
[37] Saak, A.E., and J.M. Peterson. Groundwater pumping by heterogeneous users. Hydrogeology Journal 20, no. 5 (2012): 835-849.

[38] Sands, Ron. With Adequate Productivity Growth, Global Agriculture Is Resilient to Future Population and Economic Growth. Amber Waves (2014): 1B.

[39] Scheierling, S. M., J. B. Loomis, and R. A. Young (2006), Irrigation water demand: A meta-analysis of price elasticities, Water Resour. Res., 42, W01411, doi:10.1029/2005WR004009.

[40] Slogget, G., and H.P. Mapp, An analysis of rising irrigation costs in the great plains, Water Resources Bulletin, 1984,20 (2): 229-233.

[41] Steward, D.R., and A.J. Allen, Peak groundwater depletion in the High Plains Aquifer, projections from 1930 to 2110. Agricultural Water Management, 170 (2016): 36-48.

[42] Suter, J. F., J. M. Duke, K. D. Messer, and H. A. Michael (2012). Behavior in a spatially explicit groundwater resource: Evidence from the lab. American Journal of Agricultural Economics 94 (5), 1094-1112.

[43] Tomini, Agnes. Is the Gisser and Sanchez model too simple to discuss the economic relevance of groundwater management?. Water Resources and Economics 6 (2014): $18-29$.

[44] Xabadia, Angela, R. Goetz, and David Zilberman. Optimal dynamic pricing of water in the presence of waterlogging and spatial heterogeneity of land. Water resources research 40, no. 7 (2004). 


\section{$6 \quad$ Figures}

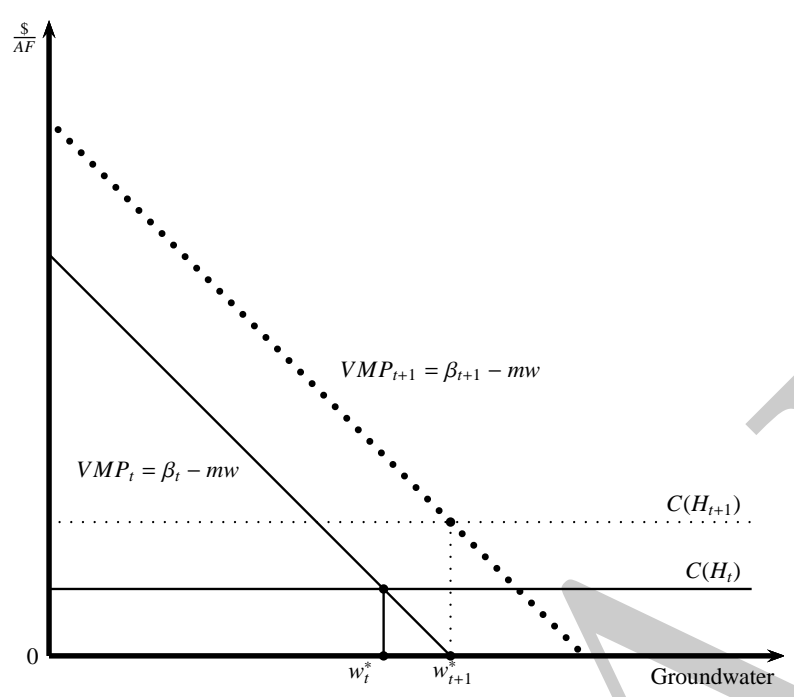

(a) Increasing groundwater use.

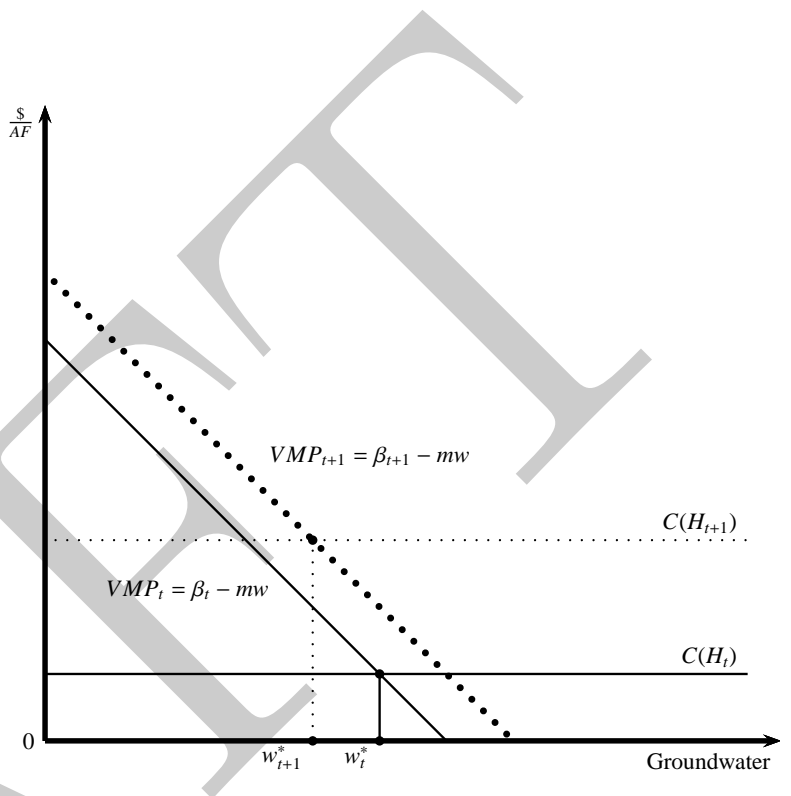

(b) Decreasing groundwater use.

Figure 1: Marginal cost and value of groundwater changing over time.

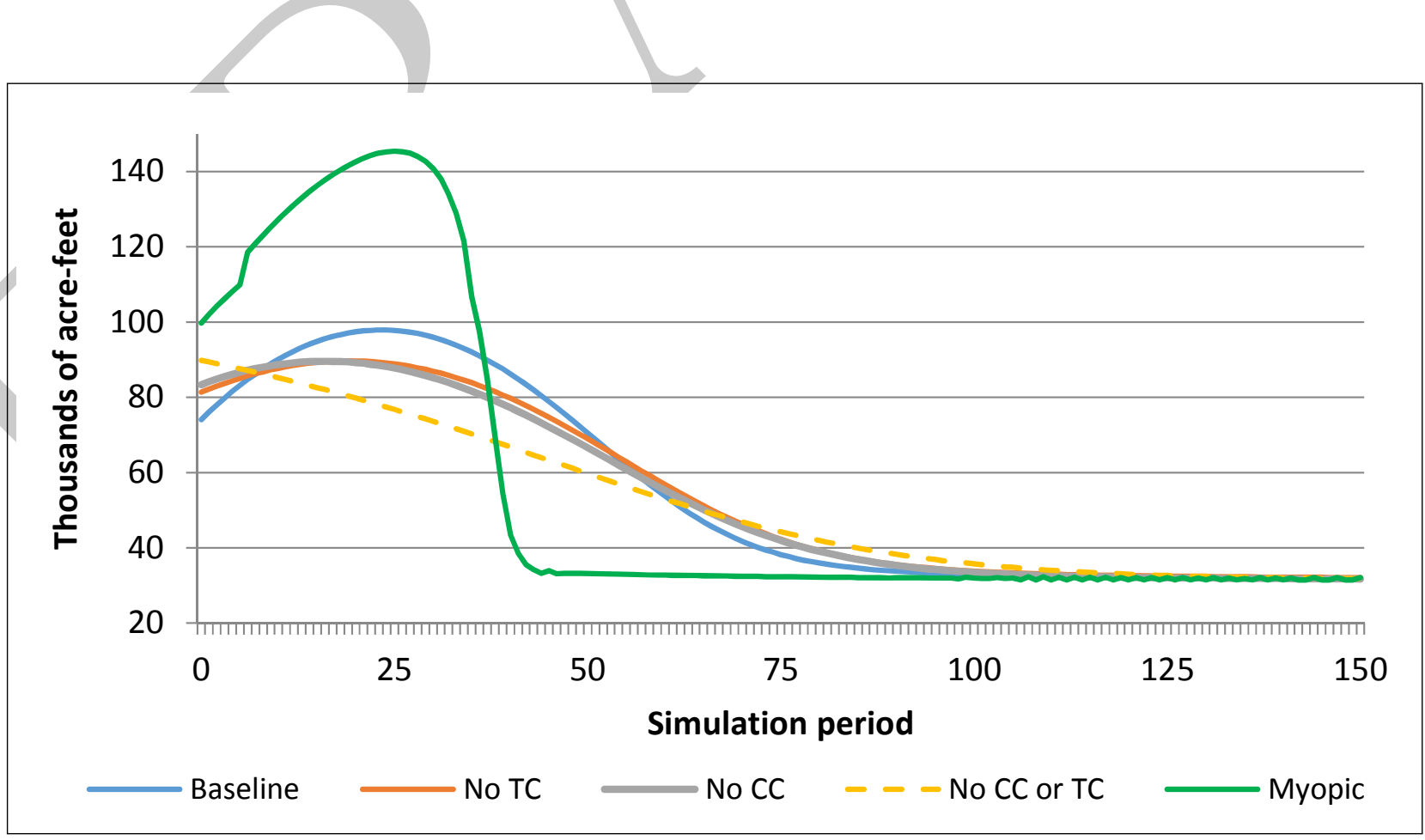

Figure 2: Periodic groundwater allocation under different planning scenarios versus the myopic scenario. 


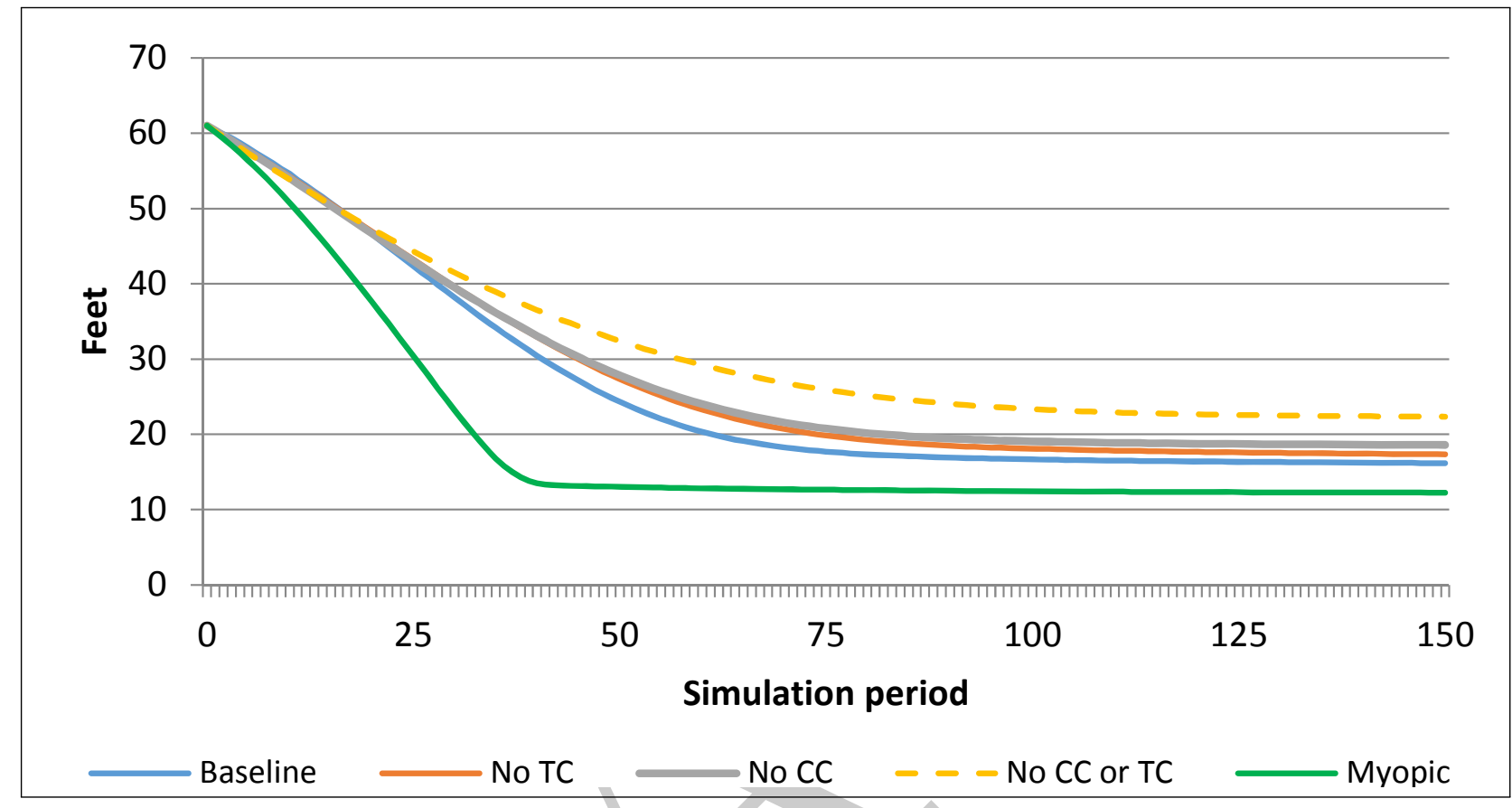

Figure 3: Aquifer saturated thickness under different planning scenarios versus the myopic scenario.

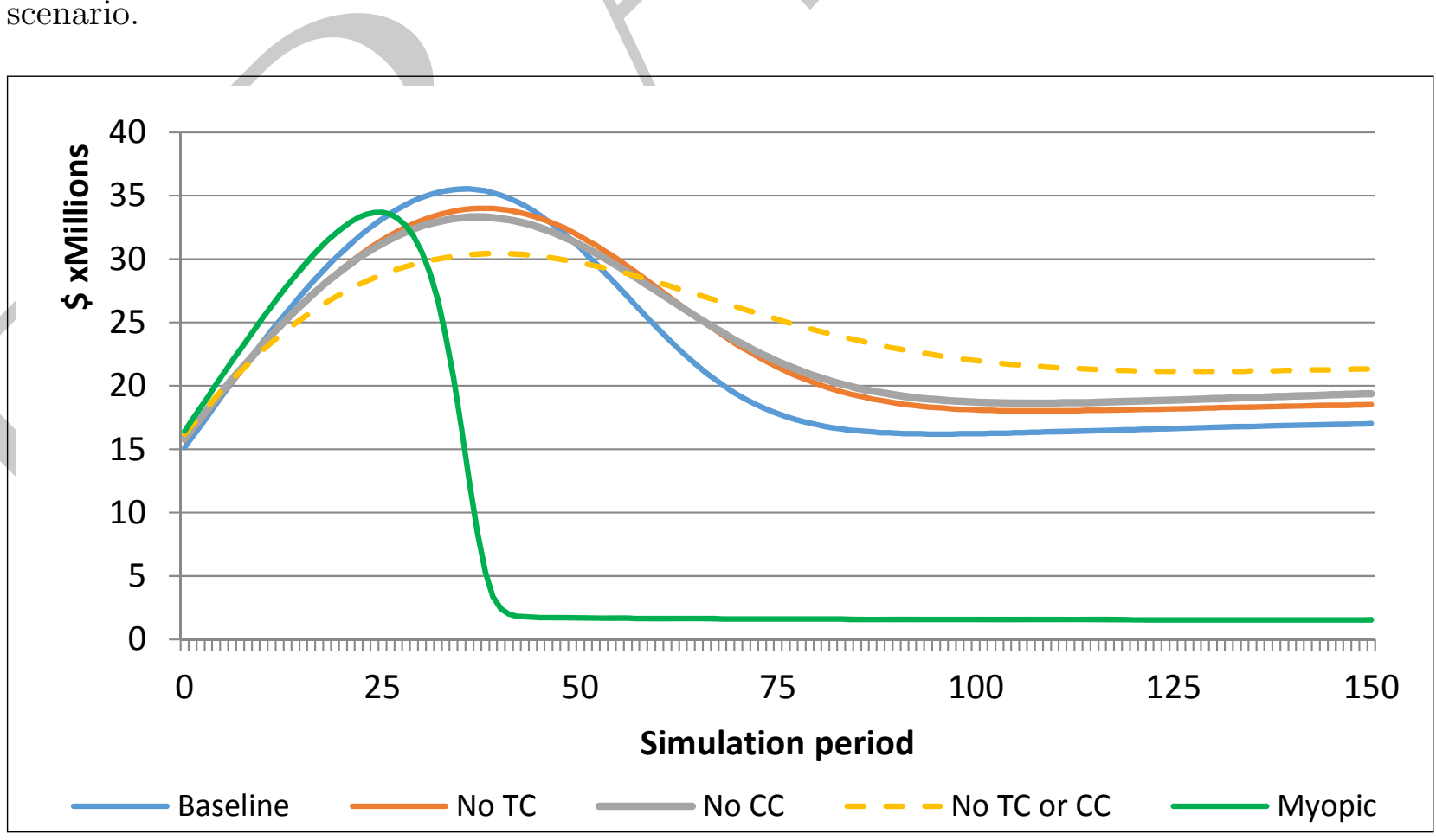

Figure 4: Periodic rents from irrigation under different planning scenarios versus the myopic scenario evaluated when both climate and technical change realize. 


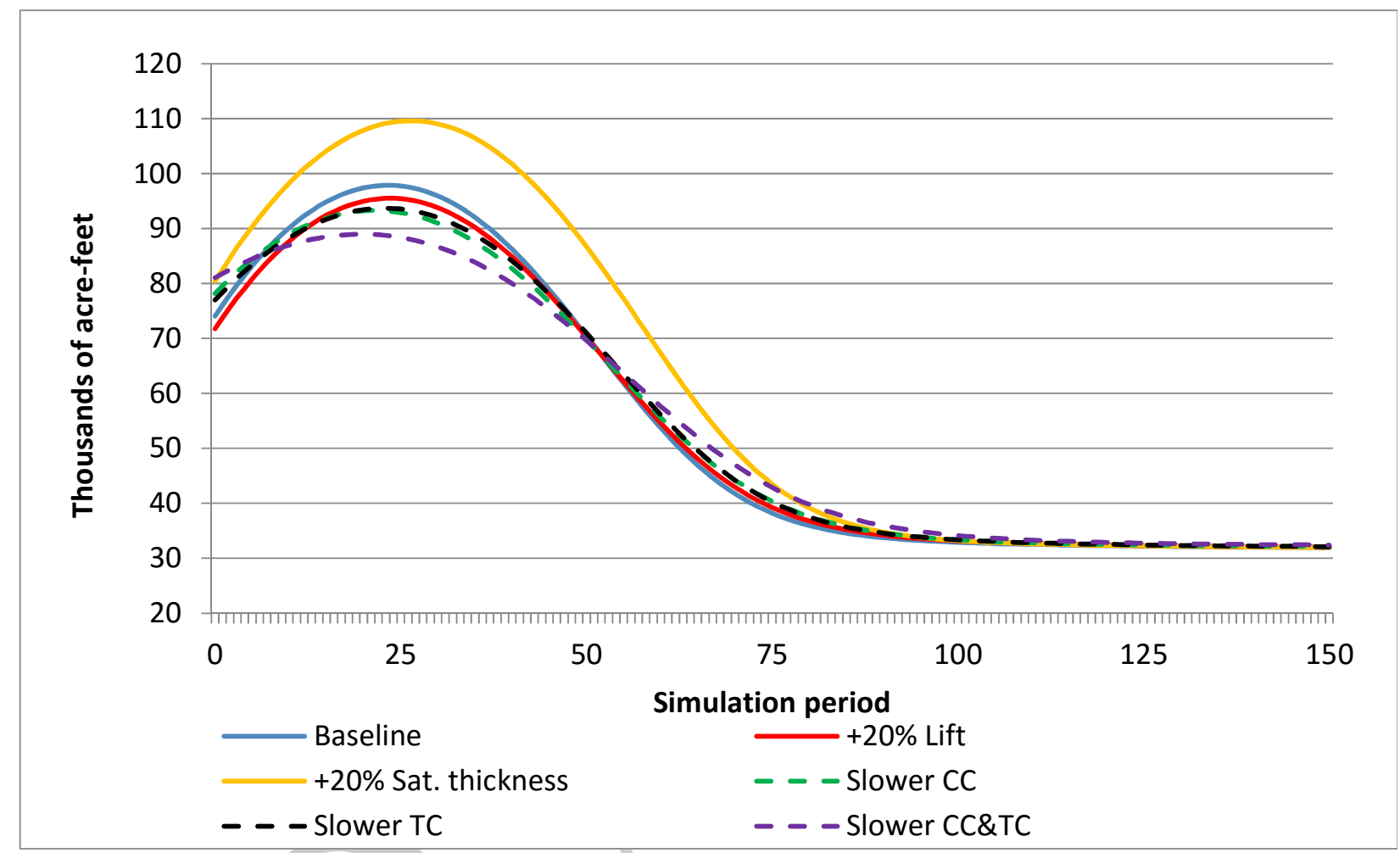

Figure 5: Optimal extraction paths under alternative initial conditions and parameters.

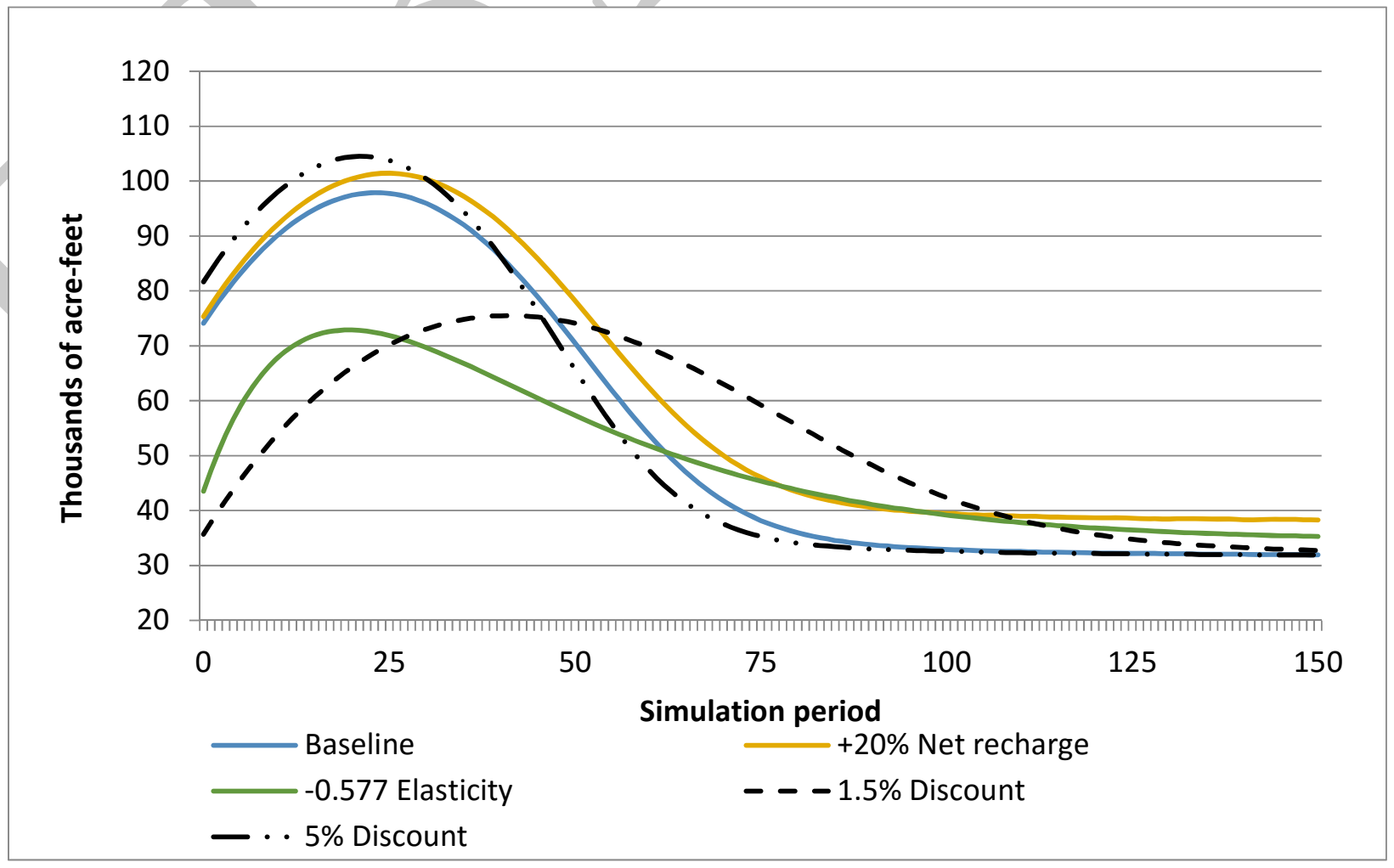

Figure 6: Optimal extraction paths under alternative initial conditions and parameters. 


\section{Tables}

\begin{tabular}{lc}
\hline \hline Parameter & Value \\
\hline \hline Aquifer & $716,844.54$ \\
Area over aquifer $\times$ specific yield $\left(A_{S}\right)$ & 77,745 acres \\
Irrigated area & 0.086795 \\
Return flow $(\alpha)$ & $111.5 \mathrm{ft}$. \\
Initial lift (depth to water) & $61.03 \mathrm{ft}$. \\
Initial saturated thickness & $20 \mathrm{ft}$. \\
Drawdown & $28,747.08 \mathrm{AF} / \mathrm{yr}$ \\
Rate of natural recharge $(r)$ & 0.0389 \\
Discount rate $(\rho)$ & \\
\hline Demand function & 232.67 \\
$\tilde{\beta}_{0}$ & 44.548 \\
Coefficient on $J: \beta_{1}$. & 18.383 \\
Coefficient on $M: \beta_{2}$. & 15.055 \\
Coefficient on $E: \beta_{3}$. & 0.0031 \\
Coefficient on $w: \beta_{4}$. & \\
\hline Cost function & $S_{L}=2,755$ \\
$C_{0}=0.975$ & $H_{0}=2,644.2 \mathrm{ft}$. \\
$Q_{0}=3.48 E-07$ & $H_{c}=2,583.2$ \\
\hline Technical change & $\beta_{0}(0)=232.67$ \\
$\dot{\beta_{0}}=10.134-0.024 \beta_{0}$ & \\
\hline Climate change & $J_{0}=4.31^{\prime \prime}$ \\
$\dot{J}=0.071833-0.01333 J$ & $M_{0}=12.37^{\prime \prime}$ \\
$\dot{M}=0.1484-0.01333 M$ & $E_{0}=35.14^{\prime \prime}$ \\
\hline \hline
\end{tabular}

Table 1: Parameters and aquifer initial values for Sheridan Co.,KS 


\begin{tabular}{|l|c|c|r|c|}
\hline \hline \multicolumn{1}{|c|}{ Plan } & $\begin{array}{c}\text { NPV } \\
(\$ \times \text { millions })\end{array}$ & $\begin{array}{c}\text { Gains from } \\
\text { Management }\end{array}$ & $\begin{array}{c}\text { Total GW } \\
(A F \times 1,000)\end{array}$ & $\begin{array}{c}\text { GW } \\
\text { Savings }\end{array}$ \\
\hline Baseline & 685.13 & $29.5 \%$ & $9,863.5$ & $2.9 \%$ \\
No TC & 681.71 & $28.8 \%$ & $9,776.6$ & $3.8 \%$ \\
No CC & 679.55 & $28.4 \%$ & $9,663.0$ & $4.9 \%$ \\
No CC or TC & 659.34 & $24.6 \%$ & $9,368.9$ & $7.8 \%$ \\
Myopic & 529.13 & & $10,161.9$ & \\
\hline \hline
\end{tabular}

Table 2: Net present value of rents from irrigation and accumulated groundwater extraction.

\begin{tabular}{|c|c|c|c|c|}
\hline & \multicolumn{4}{|c|}{ Realized Scenario } \\
\hline & \multicolumn{2}{|c|}{ Climate Change Occurs } & \multicolumn{2}{|c|}{ No Climate Change Occurs } \\
\hline Plan & TC Occurs & No TC Occurs & TC Occurs & No TC Occurs \\
\hline Baseline & $29.5 \%$ & $30.1 \%$ & $20.0 \%$ & $0.9 \%$ \\
\hline No TC & $28.8 \%$ & $30.9 \%$ & $21.4 \%$ & $4.0 \%$ \\
\hline No CC & $28.4 \%$ & $30.8 \%$ & $21.5 \%$ & $4.6 \%$ \\
\hline No $\mathrm{CC}$ or $\mathrm{TC}$ & $24.6 \%$ & $28.6 \%$ & $20.0 \%$ & $6.1 \%$ \\
\hline
\end{tabular}

Table 3: Evaluation of gains from plans under different realized scenarios.

\begin{tabular}{|l|c|c|r|c|c|}
\hline \hline \multicolumn{1}{|c|}{ Plan } & $\begin{array}{c}\text { NPV } \\
\text { millions })\end{array}$ & $\begin{array}{c}\text { Gains from } \\
\text { Management }\end{array}$ & $\begin{array}{c}\text { Total GW } \\
(A F \times 1,000)\end{array}$ & $\begin{array}{c}\text { GW } \\
\text { Savings }\end{array}$ & $\begin{array}{c}\text { Effect on } \\
\text { Welfare }\end{array}$ \\
\hline \hline Baseline & 685.13 & $29.5 \%$ & 9,863 & $2.9 \%$ & $(-)$ \\
\hline +20\% Lift & 618.28 & $16.2 \%$ & 9,243 & $10.0 \%$ & $(+)$ \\
\hline +20\% Sat. thick. & 710.72 & $15.1 \%$ & 10,219 & $8.7 \%$ & $(+)$ \\
\hline +20\% Net rech. & 716.93 & $29.3 \%$ & 11,088 & $3.0 \%$ & $(++)$ \\
\hline Slower TC & 626.76 & $18.5 \%$ & 9,857 & $3.0 \%$ & $(--)$ \\
\hline Slower CC & 603.55 & $14.1 \%$ & 9,832 & $3.1 \%$ & $(--)$ \\
\hline Slower CC\&TC & 546.77 & $3.3 \%$ & 9,823 & $3.1 \%$ & $(---)$ \\
\hline $\mathbf{- 0 . 5 7 7}$ Elasticity & 303.21 & $106.8 \%$ & 19,536 & $\approx 0$ & $(+++)$ \\
\hline $\mathbf{1 . 5 \%}$ Discount & $1,423.20$ & $77.9 \%$ & 6,241 & $10.8 \%$ & $(+++)$ \\
\hline $\mathbf{5 \%}$ Discount & 532.80 & $18.8 \%$ & 9,906 & $2.5 \%$ & $(---)$ \\
\hline \hline
\end{tabular}

Table 4: Net present value of benefits and groundwater extraction for first 200 years under alternative scenarios. 


\section{Appendix A}

The LQ problem has the form:

$$
\begin{aligned}
R(w ; \beta, H) & =B(w ; \beta)-C(H) w \\
& =\left(\beta-\frac{1}{2} \gamma w\right) w-\frac{1}{2} c_{2} H^{2}-\left(c_{0}+c_{1}(S-H)\right) w \\
& =\left(\beta-c_{0}-c_{1} S\right) w-\frac{1}{2} \gamma w^{2}-\frac{1}{2} c_{2} H^{2}-c_{1} H w
\end{aligned}
$$

where

$$
\begin{gathered}
\beta=\frac{b_{0}}{b_{1}}+\left(\tilde{\beta}-\frac{b_{0}}{b_{1}}\right) \exp \left[-b_{1} t\right] \\
\dot{H}=g(w, H)=n-a w
\end{gathered}
$$

where $\tilde{\beta}$ is the initial value of $\beta, n=\frac{r}{A s}, a=\frac{1-\alpha}{A s}, r$ is rate of net recharge, $\alpha$ is return flows, and $A s$ is area overlying the aquifer times specific yield. A well behaved reward function requires $c_{2}>\frac{c_{1}^{2}}{\gamma}$.

Solving the control problem yields a $3 \times 3$ linear dynamical system:

$$
\dot{x}=\left[\begin{array}{c}
\dot{\beta} \\
\dot{H} \\
\dot{w}
\end{array}\right]=\left[\begin{array}{ccc}
-b_{1} & 0 & 0 \\
0 & 0 & -a \\
-\left(b_{1}+\rho\right) & \left(\rho c_{1}-a c_{2}\right) & \rho \gamma
\end{array}\right]\left[\begin{array}{l}
\beta \\
H \\
w
\end{array}\right]+\left[\begin{array}{l}
b_{0} \\
n \\
\theta_{1}
\end{array}\right]=A x+b
$$

where $\theta_{1}=b_{0}-c_{1} n+\rho c_{0}+\rho c_{1} S$. 
The steady state is given by $\dot{x}=0$.

$$
\begin{aligned}
x_{\infty}^{*}=-A^{-1} b & =\left[\begin{array}{ccc}
-b_{1} & 0 & 0 \\
0 & 0 & -a \\
-\left(b_{1}+\rho\right) & \left(\rho c_{1}-a c_{2}\right) & \rho \gamma
\end{array}\right]^{-1}\left[\begin{array}{l}
b_{0} \\
n \\
\theta_{1}
\end{array}\right] \\
& =\left[\begin{array}{cc}
\frac{b_{0}}{b_{1}} \\
\frac{\theta_{1}}{a c_{2}-\rho c_{1}}-\frac{b_{0}}{a b_{1} c_{2}-\rho b_{1} c_{1}}\left(\rho+b_{1}\right)+n \gamma \frac{\rho}{a^{2} c_{2}-a \rho c_{1}}
\end{array}\right]
\end{aligned}
$$

And the trajectories over time depend on the (negative) eigenvalues and eigenvectors of matrix A. Eigenvalues: $\lambda_{1}=\frac{1}{2} \gamma \rho-\frac{1}{2} \sqrt{4 c_{2} a^{2}-4 c_{1} a \rho+\gamma^{2} \rho^{2}}<0 \Longleftrightarrow \rho c_{1}<a c_{2} c_{2}<\frac{a}{\rho}$,

$$
\begin{aligned}
& \lambda_{2}=\frac{1}{2} \gamma \rho+\frac{1}{2} \sqrt{4 c_{2} a^{2}-4 c_{1} a \rho+\gamma^{2} \rho^{2}}>0, \\
& \lambda_{3}=-b_{1}<0
\end{aligned}
$$

with associated eigenvectors:

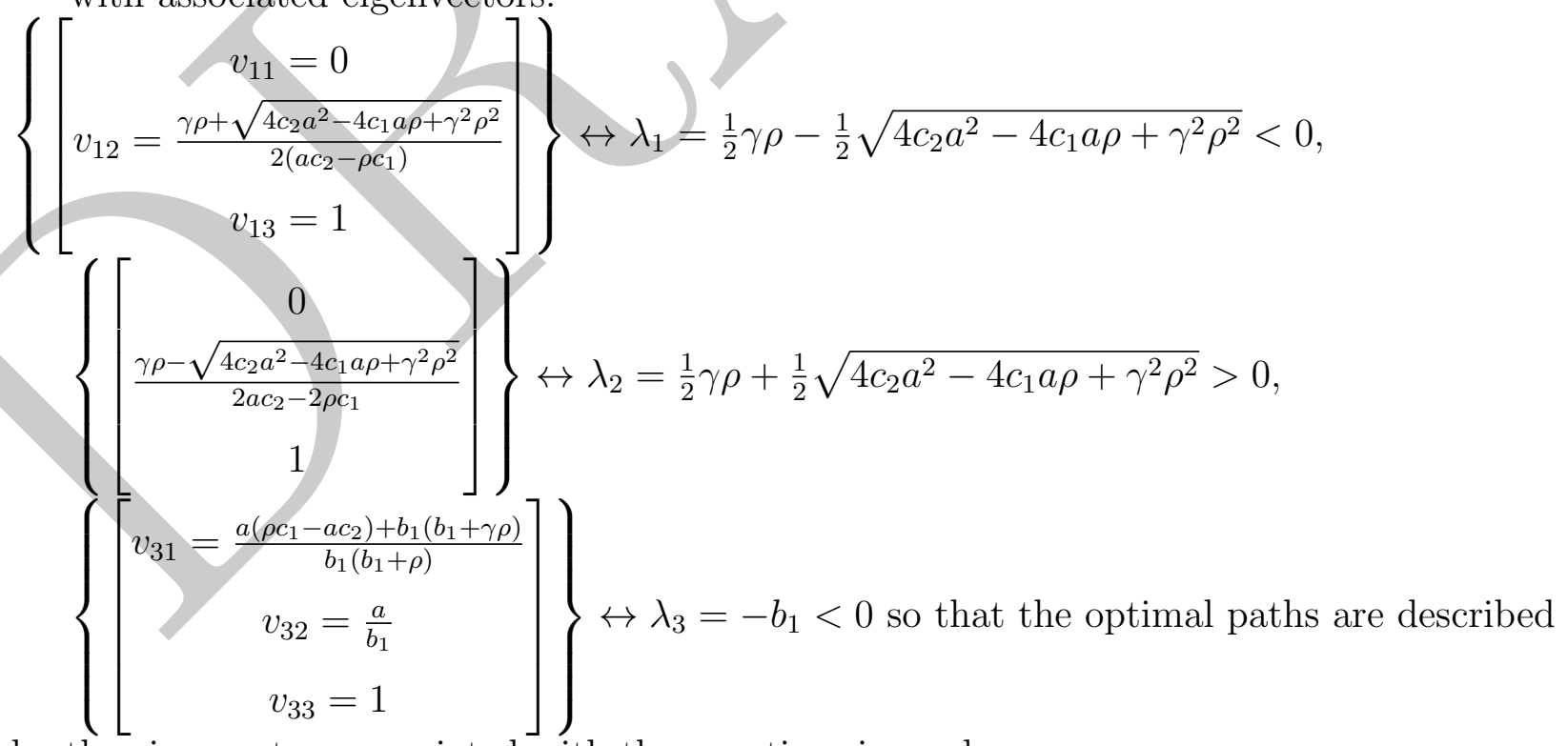

by the eigenvectors associated with the negative eigenvalues:

$$
\begin{aligned}
\beta^{*}(t) & =\beta_{\infty}^{*}+k_{3} v_{31} e^{\lambda_{3} t}+k_{1} v_{11} e^{\lambda_{1} t} \\
H^{*}(t) & =H_{\infty}^{*}+k_{3} v_{32} e^{\lambda_{3} t}+k_{1} v_{12} e^{\lambda_{1} t} \\
u^{*}(t) & =u_{\infty}^{*}+k_{3} v_{33} e^{\lambda_{3} t}+k_{1} v_{13} e^{\lambda_{1} t}
\end{aligned}
$$


where

$$
\begin{aligned}
& k_{1}=\frac{H_{0}-H_{\infty}^{*}}{v_{12}} \\
& k_{3}=\frac{\beta_{0}-\beta_{\infty}^{*}}{v_{31}}
\end{aligned}
$$

The optimal paths are

$$
\begin{gathered}
\beta_{t}^{*}=\beta_{\infty}^{*}+\left(\beta_{0}-\beta_{\infty}^{*}\right) e^{-b_{1} t} \\
H_{t}^{*}=H_{\infty}^{*}+\left(\beta_{0}-\beta_{\infty}^{*}\right)\left(\frac{a\left(b_{1}+\rho\right)}{a\left(\rho c_{1}-c_{2} a\right)+b_{1}\left(b_{1}+\gamma \rho\right)}\right) e^{-b_{1} t} \\
+\left(H_{0}-H_{\infty}^{*}\right) e^{\lambda_{1} t} \\
u_{t}^{*}=u_{\infty}^{*}+\left(\beta_{0}-\beta_{\infty}^{*}\right)\left(\frac{b_{1}\left(b_{1}+\rho\right)}{a\left(\rho c_{1}-c_{2} a\right)+b_{1}\left(b_{1}+\gamma \rho\right)}\right) e^{-b_{1} t} \\
+\frac{2\left(H_{0}-H_{\infty}^{*}\right)\left(a c_{2}-\rho c_{1}\right)}{\gamma \rho+\sqrt{4 c_{2} a^{2}-4 c_{1} a \rho+\gamma^{2} \rho^{2}}} e^{\lambda_{1} t}
\end{gathered}
$$

As the LQ problem results in optimal control that is linear in the state variables:

$$
u^{*}=V+W_{1} \beta+W_{2} H
$$

where

$$
V=u_{\infty}^{*}-\left(\frac{v_{33} v_{12-} v_{32} v_{13}}{v_{31} v_{12}}\right) \beta_{\infty}^{*}-\frac{v_{13}}{v_{12}} H_{\infty}^{*}
$$

$$
\begin{aligned}
W_{1}=\frac{v_{33} v_{12}-v_{13} v_{32}}{v_{31} v_{12}} & \\
= & \frac{b_{1}\left(b_{1}+\rho\right)}{a\left(\rho c_{1}-a c_{2}\right)+b_{1}\left(b_{1}+\gamma \rho\right)}\left(1-\frac{a}{b_{1}}\left(\frac{2 a\left(a c_{2}-\rho c_{1}\right)}{\gamma \rho+\sqrt{4 a\left(a c_{2}-\rho c_{1}\right)+\gamma^{2} \rho^{2}}}\right)\right)>0 \\
W_{2}=\frac{v_{13}}{v_{12}} & =\frac{2\left(a c_{2}-\rho c_{1}\right)}{\gamma \rho+\sqrt{4 c_{2} a^{2}-4 c_{1} a \rho+\gamma^{2} \rho^{2}}}>0
\end{aligned}
$$

The sign of $W_{2}$ follows from the condition on $\lambda_{1}<0$. The sign of $W_{1}$ can not 


\begin{tabular}{|l|c|c|c|c|c|c|}
\hline \hline & $\rho$ & $b_{1}$ & $c_{1}$ & $c_{2}$ & $\gamma$ & $a$ \\
\hline Min & 0.000 & 0.016 & 0.1824 & 32.162 & 0.00015 & 0.0000000144 \\
Base & 0.0389 & 0.024 & 0.6689 & 64.324 & 0.0031 & 0.0000002198 \\
Max & 0.1000 & 0.044 & 1.3378 & 128.65 & 0.0301 & 0.0008506944 \\
\hline \hline
\end{tabular}

Table 5: Range of plausible parameter values for signing $W_{1}$.

unequivocally be determined from necessary or sufficient conditions. Consequently a lower and upper limit for admissible parameter values (see table 5) are established and used along with the baseline values to calculate the value of $W_{1}$.

The values in table 5 were produced as follows:

- $\rho$ is the social discount rate conventionally set to account for the value of immediacy. In investment decisions it is set as to reflect the cost of capital. In our paper we use the average interest rate for farm loans as described (3.87 percent). The lower limit is set at 0 percent. The upper limit is set at 10 percent (the highest average farm mortgage rate is as high as 5.7 percent in the Dallas Fed area).

- $b_{1}<1$ is the coefficient that determines the rate of change of $\beta$ and its steady state. This is a calibrated parameter that depends on initial conditions, assumption of initial level of productivity increase and steady state productivity level $\left(\beta_{\infty}=b_{0} / b_{1}\right)$, which this paper assumes to be twice that of the initial productivity $\left(b_{1}=0.024\right)$. Supposing the steady state could be as low as 10 percent higher than starting levels, we have that $b_{1}=0.0436$. If productivity is three times larger, $b_{1}=0.016$.

- $c_{1}$ is the cost of pumping one AF of groundwater at the initial lift. This parameter is calculated based on engineering formulas yielding an average of 0.6689 for a marginal cost of $\$ 22 / A F$ at the initial state. A lower-bound is set at $\$ 6 / A F$ yielding a parameter value of 0.1824 . The upper bound is set at twice the base value at $\$ 44 / A F$ yielding a coefficient value of 1.3378 .

- $c_{2}$ is a coefficient that accounts for the nonlinear impact of a decreasing aquifer. The 
value is calibrated based on nonlinear marginal pumping costs calculations based on a model of declining well yields at 64.324. The lower and upper limits are set at half and double those levels (32.162 and 128.648).

- $\gamma$ is the absolute value of the slope of the groundwater inverse demand curve. The base coefficient is 0.0031 ( -0.11 elasticity). An arbitrary upper limit is set at 0.01 which is equivalent to an elasticity of -0.03 . Pfeiffer and Lin (2014) posit that elasticities may be underestimated in groundwater demand studies. Scheierling et al. (2006) presents a meta-analysis of irrigation water demand studies to that point with elasticity values as high as 1.86 for Howe et al. (1971). The lower limit is then set for an elasticity of -2 which equates to a coefficient value of 0.00015 .

- $a=(1-\alpha) / A_{S}$ is an aquifer depletion coefficient that determines how much the water table elevation changes for every AF of groundwater extracted. $\alpha$ is the portion of applied water that returns to the aquifer.Specific yield ranges from 5 to 25 percent. Consumptive use could be interpreted as the application efficiency which varies according to the irrigation system. Howell (2003) shows the range of application efficiency observable, which can be as low as 40 percent for flood irrigation (up to 70 percent) and as high as 98 percent for LEPA center pivot (92 percent average, 80 percent minimum) with low efficiency center pivots. The lower limit is established considering the area of the whole High Plains aquifer (174,000sq.miles), specific yield of 25 percent and application efficiency of 40 percent so that $a=0.0000000144$. The upper limit is established for 98 percent efficiency on a 36sq.mile area (size of a township) with 5 percent specific yield so that $a=0.008506944$. The used value is $a=0.0000002198$ for the average application efficiency and specific yield as well as the area for Sheridan county, KS.

There are six parameters with three levels each, i.e. (min, base, max), so that there are $3^{6}=729$ calculations for the coefficient. Every calculation yields $W_{1}>0$, even those 
violating $c_{2} \gamma>c_{1}^{2}$ and $a c_{2}>\rho c_{1}$. In only 23 admissible cases we see that $a\left(a c_{2}-\rho c_{1}-\right)<b_{1}\left(b_{1}+\gamma \rho\right)$ and $\frac{a}{b_{1}}\left(\frac{2 a\left(a c_{2}-\rho c_{1}\right)}{\gamma \rho+\sqrt{4 a\left(a c_{2}-\rho c_{1}\right)+\gamma^{2} \rho^{2}}}\right)>1$; all of which require the highest discount rates and the lowest terminal productivity (10 percent higher than in the present), failing any of these two conditions, the inequalities reverse.

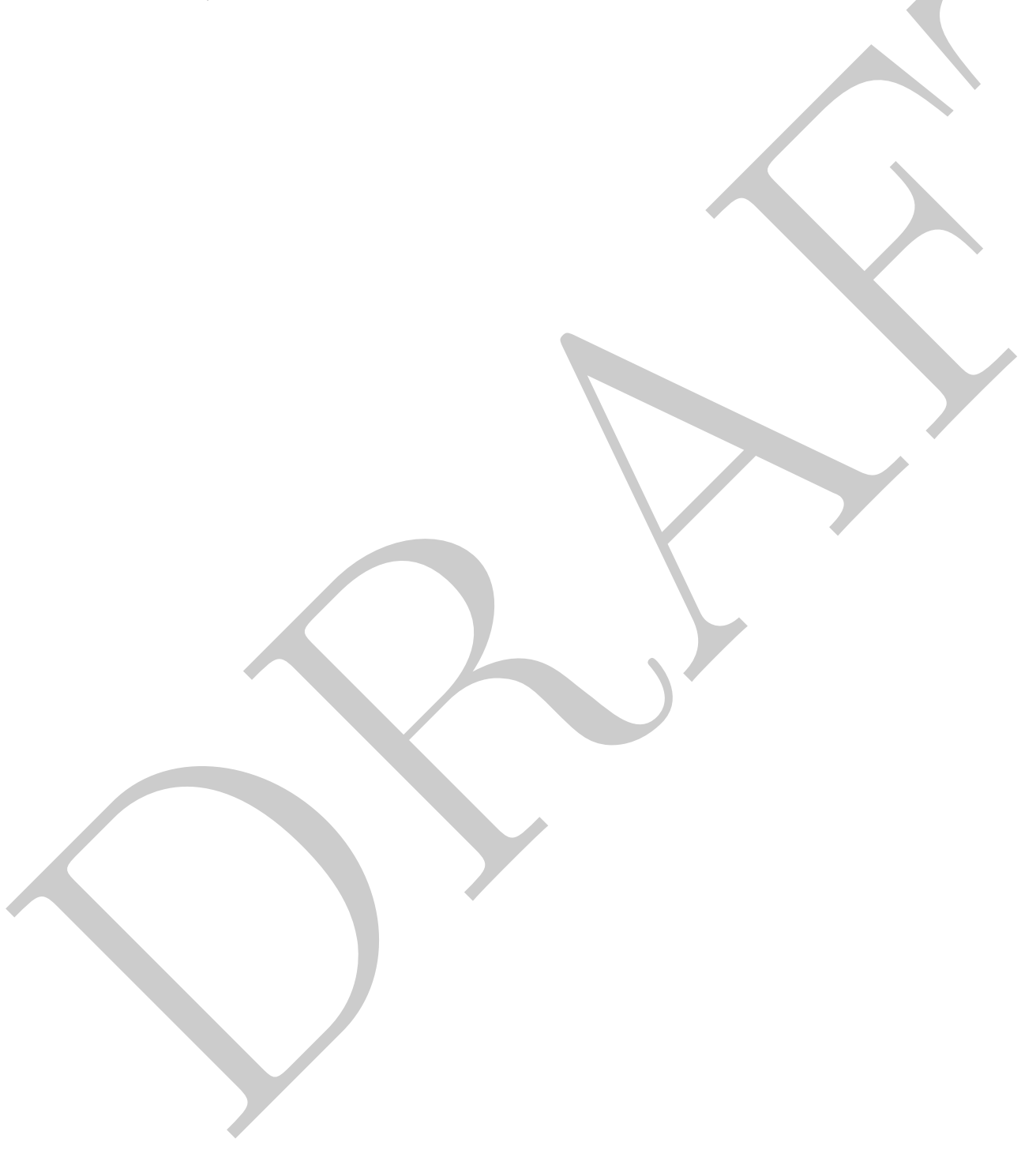

